\title{
The body plan of Halszkaraptor escuilliei (Dinosauria, Theropoda) is not a transitional form along the evolution of dromaeosaurid hypercarnivory
}

\author{
Andrea Cau ${ }^{\text {Corresp. } 1}$ \\ 1 Independent, Parma, Italy \\ Corresponding Author: Andrea Cau \\ Email address: cauand@gmail.com
}

The dromaeosaurid theropod Halszkaraptor escuilliei is characterized by several unusual features absent in other paravians, part of which has been interpreted as diagnostic of a novel lineage adapted to a semiaquatic ecology. Recently, these evolutionary and ecological interpretations have been challenged, and Halszkaraptor has been claimed to be a transitional form between non-dromaeosaurid maniraptoriforms and other dromaeosaurids: following that re-evaluation, its peculiar body plan would represent the retention of several maniraptoran plesiomorphies, lost among other dromaeosaurids, and not an adaptation to a novel ecology. This alternative scenario is here carefully investigated and tested. It is shown that most statements supporting this scenario are based on misinterpretation of anatomical traits and bibliography. Once these statements have been corrected, character state transition optimization over a well-supported phylogenetic framework indicates that the large majority of the peculiar features of the Halszkaraptor lineage are derived novelties acquired by the latter after its divergence from the last ancestor shared with eudromaeosaurs, and thus are not maniraptoriform plesiomorphies. At least seven novelties of the Halszkaraptor lineage are convergently acquired with spinosaurids, and are integrated in semiaquatic adaptations: one of these is reported here for the first time. The amount of morphological divergence of Halszkaraptorinae from the ancestral dromaeosaurid condition is comparable to those of Microraptorinae and Velociraptorinae. Among extant taxa, the sawbills (Mergini, Anseriformes) show the closest ecomorphological similarity with the peculiar body plan inferred for Halszkaraptor. The halszkaraptorine bauplan is thus confirmed as a peculiar amphibious specialization, and does not represent a "transitional" stage along the evolution of dromaeosaurids. 


\section{The body plan of Halszkaraptor escuilliei (Dinosauria, Theropoda) is}

2 not a transitional form along the evolution of dromaeosaurid

\section{3 hypercarnivory}

\section{Andrea $\mathrm{Cau}^{1}$}

$6 \quad{ }^{1}$ Independent, Parma, Italy

7 Email address: caudand@gmail.com

\section{ABSTRACT}

10 The dromaeosaurid theropod Halszkaraptor escuilliei is characterized by several unusual features absent in other 11 paravians, part of which has been interpreted as diagnostic of a novel lineage adapted to a semiaquatic ecology.

12 Recently, these evolutionary and ecological interpretations have been challenged, and Halszkaraptor has been

13 claimed to be a transitional form between non-dromaeosaurid maniraptoriforms and other dromaeosaurids:

14 following that re-evaluation, its peculiar body plan would represent the retention of several maniraptoran

15 plesiomorphies, lost among other dromaeosaurids, and not an adaptation to a novel ecology. This alternative scenario is here carefully investigated and tested. It is shown that most statements supporting this scenario are based on misinterpretation of anatomical traits and bibliography. Once these statements have been corrected, character state transition optimization over a well-supported phylogenetic framework indicates that the large majority of the peculiar features of the Halszkaraptor lineage are derived novelties acquired by the latter after its divergence from the last ancestor shared with eudromaeosaurs, and thus are not maniraptoriform plesiomorphies. At least seven novelties of the Halszkaraptor lineage are convergently acquired with spinosaurids, and are integrated in semiaquatic adaptations: one of these is reported here for the first time. The amount of morphological divergence of Halszkaraptorinae from the ancestral dromaeosaurid condition is comparable to those of Microraptorinae and Velociraptorinae. Among extant taxa, the sawbills (Mergini, Anseriformes) show the closest ecomorphological similarity with the peculiar body plan inferred for Halszkaraptor. The halszkaraptorine bauplan is thus confirmed as a peculiar amphibious specialization, and does not represent a "transitional" stage along the evolution of dromaeosaurids.

\section{INTRODUCTION}

31 The bird-like theropod dinosaur Halszkaraptor escuilliei is a based on an almost complete 32 skeleton from the Upper Cretaceous of Mongolia (Cau et al., 2017). Compared to other 
33 theropods, Halszkaraptor shows several unusual features, supporting the institution of a new

34 lineage of Dromaeosauridae, the halszkaraptorines (Cau et al., 2017; Cau \& Madzia, 2018;

35 Agnolin et al., 2018), and suggesting a semiaquatic bauplan able to exploit both terrestrial and

36 aquatic resources. Recently, Brownstein (2019) published a review of the interpretations of Cau

37 et al. (2017), and concluded that Halszkaraptor was not a semiaquatic form but a "transitional

38 form" between the plesiomorphic maniraptoriform bauplan and the hypercarnivorous

39 dromaeosaurids. Here, I show that several statements in Brownstein (2019) are unsupported,

40 inaccurate or contradictory, and that most of the arguments raised by Brownstein (2019) stem

41 from a substantial misinterpretation of the literature (in primis, but not uniquely, Cau et al. 2017)

42 or are based on problematic homology statements.

43

44

45

46

47

\section{MATERIAL AND METHODS}

Brownstein (2019) cited several statements from the literature in support of his arguments: they were carefully checked and when not corresponding to the original source, they were reported and commented. All information from H. escuilliei discussed here was acquired by AC at the Royal Belgian Institute of Natural Sciences (RBINS), Brussels, where MPC D-102/109 is temporarily housed (see Cau et al., 2017). First-hand examination of MPC D-102/109 was integrated with multi-resolution scan data of the fossil, based on propagation X-ray phasecontrast synchrotron microtomography performed in 2016, at the European Synchrotron Radiation Facility in Grenoble, France (see Cau et al., 2017). In order to test the evolutionary and phylogenetic scenario suggested by Brownstein (2019), I used a new version of the data set used in Cau et al. (2017) (Supplementary Files). The data matrix was analyzed using TNT vers. 1.5. (Goloboff et al., 2008), following the same protocol of Cau et al. (2017: a first round of 100 "New Technology" runs, using default setting, was followed by a Tree-Bisection-Reconnection run using the shortest trees saved during the first round as starting topologies). The Triassic dinosaur Herrerasaurus was used as root of the trees. Four spinosaurid taxa were included in the sample, to test the distribution of the features shared by Halszkaraptor and those noncoelurosaurian theropods (Cau et al., 2017). The "agreement subtree" algorithm implemented in TNT was used to reconstruct the taxonomically most comprehensive fully-dichotomous structure shared by all shortest trees found: for this reconstruction, max tree was set to 50.000 due to memory limitations in TNT. The agreement subtree topology was used as framework for 
64 character state reconstruction at nodes and for estimating the minimum length of the recovered 65 branches. Character state transition reconstruction at nodes was performed in PAUP (Swofford, 66 2002), importing the agreement subtree topology reconstructed in TNT and using the

67 ACCelerated TRANsformation (ACCTRAN) optimisation. Taxonomic nomenclature follows 68 Cau et al. (2017), with emendation of Unenlagiinae following Hartman et al. (2019). The 69 distribution of the reconstructed state transitions along the theropod phylogeny was used to 70 compare the alternative scenarios discussed by Cau et al. (2017) and Brownstein (2019).

71 Institutional abbreviations: MPC, Institute of Paleontology and Geology, Mongolian Academy of 72 Sciences, Ulanbatar, Mongolia; MSNM, Natural History Museum, Milan, Italy; RBINS, Royal 73 Belgian Insitute of Natural Sciences, Brussels, Belgium; YFGP, Yizhou Fossil and Geology 74 Park, Yizhou, China.

75

\section{RESULTS}

Several sentences in Brownstein (2019) are inaccurate or problematic, including mentions to statements in the literature which are actually contradicted by the mentioned references themselves. In the following references, the term "ref./refs." followed by one or more numbers refers to the reference list in Brownstein (2019).

\section{Literature misreports and unsupported statements}

Brownstein (2019) compared the premaxilla of Halszkaraptor with those of ornithomimosaurs and therizinosaurians. He wrote: "moderately to strongly (=platyrostral) laterally expanded premaxillae are found in a variety of maniraptorans and maniraptoriforms [...]. Among these, the premaxillae of Erlikosaurus are the best preserved and are highly reminiscent of the premaxillae of Halszkaraptor in their clear lateral expansion in dorsal view [...]”. Contra Brownstein (2019), it is unlikely that the platyrostral morphology of Halszkaraptor is homologous to those he referred to other coelurosaurs. In Halszkaraptor, the platyrostral condition is acquired by the remarkable anteroposterior elongation and dorsoventral flattening of the prenarial region of the premaxilla, which also results in the posterior placement of the narial region relative to the snout anterior tip. In ornithomimosaurs, the platyrostral condition is instead related to the lateral expansion of the perinarial region (e.g., Osmólska et al., 1972; Lee et al., 2014) which is not followed by any significant elongation of the prenarial region. In Erlikosaurus, the prenarial part of the premaxilla is taller than long, constrasting with the opposite condition in Halszkaraptor 
95 (Figure 1). Note that the relative elongation of the prenarial part of the premaxilla and the 96 posterior retraction of the premaxillary margin of the external naris are not co-variant and thus 97 could be considered as independent features (e.g., Haplocheirus, Choiniere et al., 2014). In 98 Erlikosaurus, the narial fossa is expanded laterally and forms the majority of the premaxillary 99 body, whereas in $H$. escuilliei the narial fossa is completely excluded from the participation to 100 the premaxillary body (Figure 1). The "lateral expansion" of the premaxilla, claimed by 101 Brownstein (2019), is thus produced by distinct elements in the two taxa (i.e., prenarial 102 elongation and depression in Halszkaraptor, vs sub- and perinarial widening in Erlikosaurus), 103 and could not be considered homologous (Figure 1).

104 Brownstein (2019) wrote: "It is unclear how Cau et al. [ref. 32] observed retracted nares in 105 Halszkaraptor, as the anterior nasals are not preserved in that taxon". Based on his own 106 statement, Brownstein (2019) assumed that the retraction of the external naris in Cau et al. 107 (2017) was meant as the position of the narial margin of the nasal. As clearly stated in the latter paper, the retraction of the external naris referred to the narial margin of the premaxilla, and not to the narial margin of the nasal. They wrote: "[T]he platyrostral premaxilla with a dorsolaterally

110 oriented external naris that is retracted beyond the oral margin is unique among theropods,

111 although in its elongation, the premaxilla is similar to those of spinosaurids" (Cau et al., 2017).

112 Brownstein (2019) thus raised a concern for a feature which actually was not discussed by Cau et 113 al. (2017). Furthermore, Brownstein (2019) wrote: "Despite the support for it found here, if the 114 presence of elongate nares is not found as the plesiomorphic state for coelurosaurs in future 115 analyses, the presence of them in a variety of theropods that do not show any features for a 116 semiaquatic lifestyle provides evidence against the argument of Cau et al. [ref. 32], who argued 117 this feature was indicative of such an ecology". Contra Brownstein's (2019) claim, Cau et al. 118 (2017) did not write that the "elongation" of the naris is present in Halszkaraptor or that it is 119 relevant in whatever ecological scenario. The actual feature mentioned by Cau et al. (2017), the 120 posterior retraction of the premaxillary narial margin beyond the premaxillary body, is absent in 121 alvarezsauroids (Choiniere et al., 2014), ornithomimosaurs (Osmólska et al., 1970; Lee et al., 122 2014), oviraptorosaurs (e.g., Balanoff et al., 2009; Balanoff et al., 2012) and therizinosauroids 123 (Lautenschlager et al., 2014), and is instead comparable to that in baryonychine spinosaurids 124 (e.g., Charig and Milner, 1997; Sereno et al., 1998), where it has been interpreted as a 125 piscivorous adaptation (Charig and Milner, 1997; Milner, 2003; Rayfield et al., 2007; see 
126 discussion in Hone and Holtz, 2017).

127 Brownstein (2019) wrote: "Although Halszkaraptor was differentiated from other theropods in

128 possessing a rostral neurovascular system not entirely restricted [to] the lateral portions of the

129 premaxillae [ref. 32], the rostral neurovasculature extends onto the dorsal surface of the body of

130 the premaxilla in basal members of most other maniraptoran clades". Several statements by

131 Brownstein (2019) inaccurately listed the external distribution and the density of the

132 neurovascular foramina in other theropods. Contra Brownstein (2019), the premaxilla of

133 Shenzhousaurus is much less extensively pitted than in Halszkaraptor (see Ji et al., 2003, ref. 13

134 cited by Brownstein, 2019). Contra Brownstein (2019), the neurovascular foramina in

135 ornithomimosaurus are densely distributed only along the oral margin but are less extensively

136 distributed (if not absent) along the rest of the premaxillary body (see Kobayashi \& Lü, 2003;

137 Ksepka \& Norell, 2004; Kobayashi \& Barsnold, 2005; Lee et al., 2014). The same condition is

138 present in oviraptorosaurs (e.g., Balanoff et al., 2009; Balanoff et al., 2012), where the

139 premaxilla is extensively pitted only along the oral margin and scarcely penetrated in the rest of

140 the bone. In all mentioned examples, the condition in these taxa differs from Halszkaraptor,

141 where the density of foramina is greater and their distribution is more extensive all along the

142 bone surface. Among theropods, only spinosaurids show a comparable density and distribution

143 of neurovascular foramina in the premaxilla (Charig and Milner, 1996; Dal Sasso et al., 2005;

144 Ibrahim et al., 2014, figure S6).

145 Furthermore, Brownstein (2019) wrote: "In the more derived therizinosaur Erlikosaurus, the

146 same morphology, where the premaxillae harbor neurovascular foramina on both their lateral and

147 mediodorsal surfaces, is clearly present (see Lautenschlager et al. [ref. 19] for clear scans of the

148 premaxillae of Erlikosaurus; Figure 1C, D)". Contra Brownstein (2019), the CT-scanning of

149 Erlikosaurus (Lautenschlager et al., 2014) demonstrates that both density and number of the

150 external foramina and the relative size of the internal plexus in that therizinosaurid are much less

151 developed than in Halszkaraptor (Figure 2). In Erlikosaurus, the external foramina are mainly

152 concentrated along the oral margin (Lautenschlager et al., 2014), and are less numerous in both

153 absolute and relative terms than in Halszkaraptor (in the latter, the dorsal surface bears at least

15420 foramina). Given that neurovascular foramina number is expected to positively correlate with

155 premaxilla size (Lautenschlager et al., 2014; David Hone, pers. com., 2019), the higher number

156 of foramina in Halszkaraptor (which bears a premaxilla about 1/5 the size of that of 
157 Erlikosaurus) is thus a very unusual condition. Furthermore, the relative size of the internal

158 neurovascular plexus (including its main stem) in Halszkaraptor is significantly larger than in

159 Erlikosaurus (Figure 2).

160 Brownstein (2019) focused his discussion on the tooth replacement patterns in Halszkaraptor

161 and assumed that its condition was comparable to those of omnivorous maniraptoriforms. He

162 wrote: "One interesting feature of the premaxillary teeth of Halszkaraptor described by Cau et

163 al. [ref. 32] was their delayed replacement rate. A large amount of research into the loss of teeth

164 in some maniraptoran dinosaurs has found a delayed replacement rate to be linked to tooth loss

165 in several clades, including therizinosaurs and ornithomimosaurs" (italics added here), and "the

166 slowly-replacing premaxillary teeth of Halszkaraptor are also reminiscent of adaptations found

167 in herbivorous theropod lineages like therizinosaurs [refs. 11, 15]". The above mentioned

168 sentences misinterpreted and misreported the literature. First, Cau et al. (2017) described a

169 "delayed replacement pattern" in Halszkaraptor, and not a "delayed replacement rate". The term

170 “delayed replacement pattern”, used by Cau et al. (2017) for Halszkaraptor, refers to the

171 differences between the premaxillary tooth-replacement compared to the maxillary tooth-

172 replacement. Second, refs. 11 and 15 mentioned by Brownstein (2019), i.e., Zanno et al. (2009),

173 and Zanno \& Makovicky (2011), do not mention "delayed replacement rate" but instead "low

174 tooth-replacement rate". The "low tooth-replacement rate" described by Zanno et al. (2009) and

175 Zanno \& Makovicky (2011), refers to the absence of pronounced replacement waves and gaps

176 between teeth, producing a continuous horizontal cutting surface (Lindsay Zanno, pers. com. ,

177 2019). Brownstein (2019) thus misinterpreted the terminology used by Cau et al. (2017) and

178 assumed that Zanno et al. (2009) and Zanno \& Makovicky (2011) referred to the same condition

179 described by Cau et al. (2017). Contra Brownstein (2019), the two terms are relative to distinct,

180 non-homologous conditions, and are not synonyms. The "low tooth-replacement rate" (Zanno et

181 al., 2009, and Zanno \& Makovicky, 2011) is absent in Halszkaraptor, which bears a sinusoid

182 cutting surface along the whole dentition and distinct replacement waves (see below, Figure 3).

183 Brownstein (2019) also stated that the "delayed replacement rate is linked to tooth loss". That

184 sentence is not correct: the absence of replacement waves in the teeth is independent to the loss

185 of teeth, as demonstrated by Pelecanimimus (Perez-Moreno et al., 1994), parvicursorines

186 (Chiappe et al., 1998) and several troodontids (e.g., Lü et al., 2010), all lacking replacement

187 waves yet retaining a complete set of teeth (Zanno \& Makovicky, 2011). Given that

PeerJ reviewing PDF | (2019:12:43616:1:1:REVIEW 10 Jan 2020) 
188 Halszkaraptor is unique among all dinosaurs in having the largest number of premaxillary teeth

189 (Cau et al., 2017), it shows a condition opposite to the loss of premaxillary teeth seen in

190 therizinosaurids or other omnivorous/herbivorous theropods (Zanno \& Makovicky, 2011). In

191 sum, Halszkaraptor is not "reminiscent of adaptations found in herbivorous theropod lineages"

192 (contra Brownstein, 2019).

193 Brownstein (2019) wrote: "Cau et al. [ref. 32] noted the comparatively long neck of

194 Halszkaraptor [...]. However, [...], it is unclear why Cau et al. allied this feature to elongate

195 necks in derived semiaquatic avians (e.g., Cygnus)". Cau et al. (2017) did not compare

196 Halszkaraptor neck elongation to the condition in derived semiaquatic avians (e.g., Cygnus). In

197 the latter study, Cygnus is only mentioned once, but in relation to the shape of the

198 interpostzygapophyseal lamina and not because of its neck elongation. Brownstein (2019)

199 misunderstood two distinct sentences in Cau et al. (2017) and combined them improperly.

200 Brownstein (2019) wrote: "Despite the fact that Cau et al. [rep. 32] claimed the neck of

201 Halszkaraptor composed the greatest percentage of snout-to-sacrum length among non-avian

202 coelurosaurs, a large number of clades include taxa that approach, reach, or possibly even

203 exceed that threshold". (Italics added here). The above statement misreports the original sentence

204 of Cau et al. (2017), which instead was: "[c]ompared to body size, the neck is elongate and forms

$20550 \%$ of the snout-sacrum length; this is the highest value found among Mesozoic paravians thus

206 far" (italics added here).

207 Brownstein (2019) wrote: "If this hypothesized ecomorphology for Halszkaraptor is correct, it

208 has major implications for the evolution of bird-like dinosaurs, with $H$. escuilliei representing the

209 first aquatic non-avian maniraptoran and suggesting that the ancestral lifestyle for

210 dromaeosaurids could be one that took place in the water [ref. 32]". Contra Brownstein (2019),

211 Cau et al. (2017) (his ref. 32) did not suggest that the ancestral dromaeosaurid lifestyle could be

212 one that took place in the water.

213 Brownstein (2019) wrote: “The Djadokhta Formation [...] preserves a highly arid environment

214 [...]. Given this environmental setting, it is hard to envision that specialized, semiaquatic

215 dromaeosaurs would populate this ecosystem”. Other Djadokhtan reptiles show adaptations

216 related to an amphibious lifestyle, like the neosuchian Shamosuchus diadochtaensis (a taxon

217 characterized by a platyrostral snout and unserrated subconical dentition; Pol et al. 2009). Even if

218 not the most abundant members, semiaquatic taxa are present in the Djadokhtan faunal 
219 assemblages (Lefeld, 1971): their relatively low frequency is in agreement with the presence of 220 ephemeral lacustrine deposits in that Formation (Dingus et al., 2008), but does not constitute a 221 challenge to the ecological interpretation of Cau et al. (2017).

222 Misreports and misinterpretation of Halszkaraptor anatomy

223 Brownstein (2019) wrote: "In many dromaeosaurids, including velociraptorines, Halszkaraptor,

224 Deinonychus, and "Bambiraptor", the anterior end of the ventral surface of the dentary bulges to

225 form a chin, as in some ornithomimosaurs". Brownstein (2019) included a drawing of the

226 anterior end of the dentary of Halszkaraptor in lateral view, and depicted a distinctly convex

227 "bulge" at the anterior end of the ventral margin (indicated in that figure by an arrow). That

228 drawing is inaccurate and misleading. The anteroventral end of the dentary in Halszkaraptor is

229 eroded (Figure 1B and 1D), so its exact shape, including the presence of the "bulge" illustrated

230 by Brownstein (2019), cannot be determined. Regardless to what actually Brownstein (2019)

231 meant with "bulge" in the dromaeosaurid dentaries, claiming its presence in Halszkaraptor is not

232 based on evidence.

233 Brownstein (2019) wrote: "On the whole, the skull of Halszkaraptor also shares many

234 similarities with basal troodontids, including [...] tightly packed teeth, and recurved, ziphodont,

235 unserrated crowns". The combination of terms "ziphodont" coupled with "unserrated" is a

236 contradiction due to the improper use of the anatomical terminology: "ziphodont" means,

237 literally, tooth with serration (Langston, 1975). The dentition of Halszkaraptor is not ziphodont.

238 In Halszkaraptor, only the premaxillary teeth are packed, a condition comparable to Microraptor

239 but absent in other microraptorines (Xing et al., 2013; Pei et al., 2014). The rest of the dentition

240 (notably, the whole maxilla) in H. escuilliei is formed by spaced alveoli with complete

241 interdental septa, differing from troodontids where the anterior maxillary dentition is formed by

242 tightly packed teeth housed in a sulcus often lacking interdental septa (e.g., Lü et al., 2010). The

243 topographical differences between the regions bearing packed teeth suggest that the condition in

244 H. escuilliei is not homologous to that in troodontids.

245 Brownstein (2019) wrote: "Shortened caudal series. Halszkaraptor possesses a highly modified

246 caudal series, a feature that Cau et al. [32] used to support a modified posture in this taxon

247 analogous to some birds". Cau et al. (2017) did not state that the caudal series of Halszkaraptor

248 is shortened. The actual number of caudal vertebrae in MPC D-102/109 is unknown, being the

249 distal end of the tail missing. The preserved part of the tail in MPC D-102/109 is comparable to 
250 the majority of paravians (e.g., Godefroit et al., 2013b; Lefèvre et al., 2017) in elongation and

251 proportions of the vertebrae, and it is not significantly reduced, as instead seen in pygostilian

252 birds or in some oviraptorosaurs (Zhou et al., 2000; Cau, 2018). Furthermore, Cau et al. (2017)

253 did not write that the unusual features in the caudal vertebrae of Halszkaraptor support a

254 modified posture like that in birds: the latter was inferred on the basis of hypertrophied origin

255 and insertion of the m. ileofibularis in, respectively, ilium and femur (Cau et al., 2017,

256 supplementary information). Brownstein (2019) thus misinterpreted two distinct and unrelated

257 sentences in Cau et al. (2017), one about the peculiar features of the caudal vertebrae (not related

258 to tail elongation/reduction), and another about the pelvic and femoral adaptations supporting

259 hip-extension.

260 Brownstein (2019) wrote: "Therefore, the cross-sectional limb morphology of Halszkaraptor

261 provides among the strongest evidence against a partially marine ecology in H. escuilliei",

262 and "[t]hese results were used to support a semiaquatic ecological mode in the taxon, with the

263 forelimb acting as a propulsion device. However, the inferences made by Cau et al. [ref. 32] from

264 the morphometric analyses are flawed, as the forelimb of Halszkaraptor looks strikingly unlike

265 the paddles formed by the forelimb bones of plesiosaurs" (Brownstein, 2019). Brownstein (2019)

266 did not provide any quantitative morphometric analysis in support of his sentences. Contra

267 Brownstein (2019), the cross-section geometry of Halszkaraptor's ulna reflects an unusual

268 flattening of the bone (a feature that was first noted in the other halszkaraptorine Mahakala, see

269 Turner et al., 2011), and recalls the analogous condition differentiating wing-propelled aquatic

270 birds from other avians (Simpson, 1946). When plotted relative to ulnar length, the mid-shaft

271 mediolateral diameter of Halszkaraptor ulnar shaft clusters it among wing-propelled birds and

272 not among other bird groups, and also results proportionally more expanded transversally than in

273 other non-avian theropods (Figure 4): this morphometric feature is consistent with the

274 ecomorphological scenario of Cau et al. (2017). Brownstein (2019) also stated: “[...] this taxon

275 [Halszkaraptor] was probably not biomechanically suited to live in water, as its skeleton, like

276 other paravians, would have probably been too light to keep the animal submerged", and "[t]he

277 bones of Halszkaraptor are clearly internally hollow to a similar extent as other paravian

278 dinosaurs. However, in tetrapods adapted for a semiaquatic or entirely aquatic lifestyle [...],

279 pachyostosis, the extreme thickening of cortical bone, occurs in the limbs. Given that

280 pachyostosis is present in the limb bones of both avian and non-avian theropods that took to the 
281 water, the absence of such thickening in Halszkaraptor, which Cau et al. [ref. 32] posit was well282 adapted for a semiaquatic ecology, would be very surprising from a biomechanical standpoint" 283 (Brownstein, 2019). In the above mentioned statements, Brownstein (2019) challenges Cau et al. 284 (2017) arguing that vertebrates with hollow long bones and a highly pneumatized postcranial 285 skeleton could not be adapted to some aquatic lifestyle, and implicitly claims that pachyostosis is 286 a necessary requisite for a semiaquatic lifestyle. Both Brownstein's (2019) assumptions are 287 falsified by several modern birds, e.g., the pelicans, characterized by an extensively-pneumatized 288 skeleton (Richardson, 1939), and that are nonetheless well-adapted to piscivory, to exploit the 289 aquatic environment and to a wing-propelled swimming style (Hinić-Frlog \& Motani, 2010). It is noteworthy that the degree of internal bone cavitation and pneumatization in the skeleton of pelicans (e.g., Simons \& O'Connor, 2012, figure 3; Wedel, 2014; Wedel, 2018) is more extensive than in Halszkaraptor.

293 Brownstein (2019) then questioned the analysis of morphospace occupation of Cau et al. (2017) which focused on the proportions of the medial fingers (I-II-III) in reptiles. He wrote: "Halszkaraptor lacks the 'paddle' in plesiosaurs, Araripemys, and other aquatic vertebrates like ichthyosaurs, wherein the hand contains many closely appressed phalanges. In contrast, the forelimbs of marine reptiles, such as mosasaurs, plesiosaurs, and ichthyosaurs, consist of a massive number of flattened, heavily modified phalanges that form a distinctive paddle shape entirely distinct from the theropod manus". Both aquatic chelonians and penguins show that a flipper- or paddle-like shape could evolve without hyperphalangy (Simpson, 1946; Walker, 1973; Clark \& Bemis, 1979; Carpenter et al., 2010). The hands of wing-propelled birds have only three fingers, with a phalangeal formula even more reduced than in Halszkaraptor

303 (Simpson, 1946). Thus, different skeletal morphologies may produce a functional paddle, which 304 is not constrained to a five-fingered pattern and to hyperphalangy. To test if the hand of 305 Halszkaraptor fits the overall proportions of a paddle, Cau et al. (2017) compared the 306 proportions of the three medialmost fingers (fingers I-II-III) in reptiles. These fingers define the 307 outline of the leading edge of the paddle, which is a key parameter in any flipper morphology 308 (Combes \& Daniel, 2001). The morphometric analysis showed that 1) there is not significant 309 overlap between theropods and other reptiles in finger proportions, 2) Halszkaraptor does not 310 cluster among the other theropods, and 3) the outline of the medial/leading edge of the hand in 311 Halszkaraptor is more similar to those of aquatic reptiles than those of the other theropods. 
312 Brownstein (2019) failed to explain why Halszkaraptor shows so unusual finger proportions: the

313 finger proportions in Halszkaraptor are not plesiomorphic for Maniraptora, and are not shared

314 with herbivorous or omnivorous theropods, and thus do not fit Brownstein's (2019) hypothesis.

315 Contra Brownstein (2019), the forelimb of Halszkaraptor markedly deviates from those of other

316 dromaeosaurids (e.g., Deinonychus, Ostrom, 1969; Microraptor, Hwang et al., 2002) in several

317 features, including the overall stouter proportions of the bones, the marked flattening of the ulna,

318 the significant reduction of the size of the first finger, the presence of a more robust third

319 metacarpal, and the significant elongation of the phalanges of the third finger: it is noteworthy

320 that all these features differentiate the forelimb of wing-propelled birds (e.g., penguins) from

321 other (i.e., non-swimming) avians (Simpson, 1949).

322 Brownstein (2019) wrote: "Their resultant reconstruction of the glenoid facing laterally in $H$.

323 escuilliei is therefore also unsubstantiated". The rationale for the inference of a laterally-facing

324 glenoid in H. escuilliei is explained by Cau et al. (2017), where it is stated: "Although the

325 fragmentary preservation of the pectoral region prevents a detailed reconstruction of forelimb

326 range of motion, on the basis of phylogenetic bracketing, we infer that the glenoid in

327 Halszkaraptor faces laterally, as it does in forelimb-assisted swimming tetrapods". A laterally-

328 facing glenoid is a paravian symplesiomorphy inherited by dromaeosaurids (Turner et al., 2012)

329 and thus, in absence of contrary evidence and based on phylogenetic bracketing, it is the most

330 plausible condition for Halszkaraptor. Given that such a feature is also an adaptation necessary

331 for any form of forelimb-assisted swimming (Carpenter et al., 2010), the plesiomorphic glenoid

332 condition of paravians which is assumed for Halszkaraptor is also a potential exaptation for a

333 forelimb-assisted swimming style.

334 Brownstein (2019) wrote: "Cau et al [32] noted that the 'sickle' claw on pedal digit II is heavily

335 reduced in Halszkaraptor compared to other dromaeosaurids". The above-mentioned statement

336 misreports Cau et al. (2017), who instead wrote: "The second toe is half the length of the third,

337 with a stout phalanx II-2 and a large falciform ungual, similar to those in other paravians".

338 (Italics added here). Contra Brownstein (2019), when pedal ungual II size of Halszkaraptor is

339 plotted against femur length (a frequently-used proxi of body size in theropod research), there is

340 no significant difference between $H$. escuilliei, the other dromaeosaurids, and other basal

341 paravians (Figure 5).

342 Inaccurate or unsupported references to other taxa 
343 Brownstein (2019) wrote: "Members of basal clades in the Dromaeosauridae, including

344 microraptorans and unenlagiines, also possess a large number $(20+)$ of teeth in their maxillae".

345 (Italics added here). All known microraptorans have less than 20 teeth in their maxillae, not more

346 (e.g., Turner et al., 2012, figure 23; Xing et al., 2013; Pei et al., 2014). Note that assuming

347 (erroneously) a larger number of maxillary teeth in microraptorans has significant implications

348 for the number of maxillary teeth inferred at the root of Dromaeosauridae (see below).

349 Brownstein (2019) wrote: "The complete connection of the postzygapophyses by bone surface

350 [as in Halszkaraptor] is present in the basal-most ornithomimosaur Nqwebasaurus and the basal-

351 most therizinosaur Falcarius, and is present to a lesser extent in basal alvarezsaurs like Aorun

352 and Haplocheirus, the basal ornithomimosaur Pelecanimimus, and the basal tyrannosauroid

353 Guanlong."

354 Contra Brownstein (2019), all the above-mentioned taxa bear distinct postzygapophyses not-

355 completely merged medially, and show posteriorly-concave interzygapophyseal laminae

356 excavated dorsally by the ligament fossa (Choiniere et al., 2010, Zanno, 2010; Choiniere et al.,

357 2012), and thus lack the autapomorphic complex of H. escuilliei.

358 Brownstein (2019) wrote: "Although it is clear that the prominence of the supratrochanteric

359 process in Halszkaraptor is greater than in these unenlagiines, the supratrochanteric process in

360 many anchiornithids is similarly developed [refs. 91, 92]". Brownstein's (2019) references 91 and

361 92, i.e., Godefroit et al. (2013a) and Godefroit et al. (2013b), do not show the supratrochanteric

362 process in anchiornithids. Furthermore, both Eosinopteryx (Godefroit et al., 2013a) and Aurornis

363 (Godefroit et al., 2013b, Figure 6A) lack a prominent supratrochanteric process like that claimed

364 by Brownstein (2019) (pers. obs., 2015). The supratrochanteric process of the anchiornithids is

365 no more developed in shape and extent than the tuber-like process present in other paravians

366 (e.g., compare Aurornis, Figure 6A, or Anchiornis, Hu et al., 2009, figure S4b, with Rahonavis,

367 Turner et al., 2012, figure 55B) and is much less prominent than in Halszkaraptor, where it

368 forms a peculiar large shelf-like lateral projection overhanging the ilium (Figure 6B).

370 Methodological weakness and non-reproducibility of the phylogenetic analysis

371 Brownstein (2019) provided a data matrix in the supplementary information of his paper.

372 Unfortunately, the phylogenetic results described in Brownstein (2019) could not be obtained

373 using the provided data matrix (i.e., the topology resulted using that data set is identical to that in 
374 Cau et al., 2017: extended data figure 10). Even more puzzling is the list of characters that

375 Brownstein (2019) claimed to form the diagnosis of the clade formed by halszkaraptorines and

376 unenlagiines, that he obtained in his analysis. He wrote: "This clade is united by five characters:

37727 (0, maxillary fenestra situated at anterior border of antorbital fossa), 107 (1, Sacral vertebrae

378 number is six), 193 (1, ascending process of astragalus short and slender), 580 ( 0 , sagittal crest of

379 parietal comprised of two parallel crests), and 828 (0, Meckelian groove centered)" (Brownstein,

380 2019). Note that character numeration does not follow entirely the original character list

381 (supplementary information of Brusatte et al., 2014): character statements \#27, \#107, \#580 and

382 \#828 in Brownstein (2019) are instead statement \#28, \#108, \#581 and \#829 in Brusatte et al.

383 (2014). Three of the above-listed character states could not be unambiguous synapomorphies of

384 the "Halszkaraptorinae + Unenlagiinae" node, because they are actually absent among

385 halszkaraptorines. The maxillary fenestra is only known in Halszkaraptor among

386 halszkaraptorines (Cau et al., 2017). In this taxon, it is placed posterodorsally on the antorbital

387 fossa and not "at anterior border of antorbital fossa": thus, character 28 of Brusatte et al. (2014)

388 cannot be scored as " 0 " in any halszkaraptorine.

389 The ascending process of the astragalus is only known in Mahakala among halszkaraptorines

390 (Turner et al., 2011). In this taxon, the ascending process is wide and covers the whole anterior

391 surface of the tibia (state 0 of character 193 of Brusatte et al., 2014), and is not slender and

392 restricted over the lateral half of the tibia as in the state "193.1" of Brusatte et al. (2014). The

393 parietal is only known in Halszkaraptor among halszkaraptorines (Cau et al., 2017). In this

394 taxon, the bone entirely lacks a sagittal crest, and thus, following the description of the character

395 in Brusatte et al. (2014), character 581 is inapplicable in Halszkaraptor.

396

397 Phylogenetic test

398 The phylogenetic analysis performed here reconstructed $>99.999$ shortest trees of 6566 steps (CI

$399=0.2333, \mathrm{RI}=0.5558$ ). The agreement subtree topology (Figure 7A) is formed by 158 of the

400 included 185 operational taxonomic units, indicating a relatively stable and well-supported

401 framework among the majority of the taxa. The relationships among the main coelurosaurian

402 clades are in agreement with the previous iterations of this data set (e.g., Cau et al., 2017; Cau,

403 2018). The analysis supports the sister group relationships between halszkaraptorines and

404 unenlagiines, as found in Cau (2018), Gianechini et al. (2018), Hartman et al. (2019), and 
405 advocated by Brownstein (2019). This clade is supported by 11 unambiguous synapomorphies

406 (Supplementary Files). Note that the result of this analysis confirms only one of the five

407 synapomorphies suggested by Brownstein (2019) in support of this clade (the presence of six

408 sacral vertebrae). Several features discussed by Brownstein (2019) and claimed in H. escuilliei

409 are falsified by a careful analysis of the morphology of Halszkaraptor and other taxa, and do not

410 support Brownstein's (2019) scenario (e.g., Halszkaraptor actually lacks the "low tooth-

411 replacement rate", a "short tail", or a "reduced" second toe ungual). Other purported features

412 listed by Brownstein (2019) cannot be considered as shared morphological character statements

413 because the condition in Halszkaraptor is not topographically homologous to those in non-

414 paravian maniraptoriforms (e.g., the "platyrostral" premaxilla of Halszkaraptor cannot be

415 homologous to those in ornithomimosaurus or therizinosauroids). Once these features are

416 removed from the list of phylogenetically significant features forming the Halszkaraptorine body

417 plan, the latter is described by 17 morphological character statements (Table 1). Character state

418 transition optimization indicates that the majority of the features (11 over 17) are evolutionary

419 novelties acquired along the "Halszkaraptorinae + Unenlagiinae" clade after its divergence from

420 the other dromaeosaurids (Table 1, Figure 7A). Seven of these halszkaraptorine novelties are

421 convergently acquired by spinosaurids (Table 1). Contra Brownstein's (2019) scenario, only two

422 among the 17 features discussed (i.e., the absence of serration in the premaxillary dentition, and

423 the presence of a robust metacarpal III) are maniraptoromorph and paravian symplesiomorphies,

424 conserved in Halszkaraptor and lost along the "microraptorine eudromaeosaurian" lineage.

425

426 DISCUSSION

427 Cau et al. (2017) interpreted the body plan of Halszkaraptor as being adapted to a peculiar

428 ecology, able to exploit both terrestrial and aquatic resources. A similar interpretation has been

429 suggested for spinosaurids (Hone and Holtz, 2017). Both terms "amphibious" and "semi-

430 aquatic" have been used differently in literature, referring to a very broad disparity of ecologies,

431 and may be misleading (see discussion in Hone and Holtz, 2017). Here, I delineate the possible

432 ecology of Halszkaraptor comparing its peculiar body plan with those of living taxa. Among

433 extant tetrapods, the sawbills (Anseriformes, Mergini, Mergus spp.) are probably the closest

434 ecological analogous to Halszkaraptor, due to a remarkable series of similarities. Sawbills are

435 long-necked birds with an elongate and moderately platyrostral snout which bears a serrated 
436 edge (analogous to a toothed oral margin), used to catch small fish and invertebrates (Kear and 437 Hulme, 2005). When moving on land, sawbills assume a distinctly erect (hip-extended) body 438 posture (Kear and Hulme, 2005); on water, they are characterized by a swimming model 439 including forelimb-propelled locomotion (Hinić-Frlog and Motani, 2010). This peculiar 440 combination of features, distinctive of sawbills, has also been inferred for Halszkaraptor (Cau et 441 al., 2017), and supports for the latter a piscivorous and aquatic ecology similar to that of the 442 mentioned avian clade.

443 The quality of the arguments provided in Brownstein (2019) in order to dismiss the main 444 conclusions of Cau et al. (2017) is dramatically weakened by a long list of inaccurate reports, 445 mostly due to the misinterpretation of the anatomical traits and bibliography. As shown above, 446 most of this rebuttal paper has been necessarily devoted to identify and correct all these 447 problematic statements, most of which are fundamental in Brownstein's (2019) alternative 448 scenario, and to remove them from the proper comparison of the two hypotheses. Brownstein 449 (2019) misinterpreted several sentences in Cau et al. (2017) and thus provided a largely 450 inaccurate and misleading depiction of the latter. Several statements that Brownstein (2019) 451 referred to Cau et al. (2017) are actually absent in the latter. The absence of polydactyly and the 452 lack of pachyostosis in Halszkaraptor are not valid arguments challenging the evolution of a 453 semiaquatic ecology, because several tetrapod lineages (including some wing-propelled diving 454 birds like pelicans) evolved such an ecology in absence of those anatomical features. Given that 455 Cau et al. (2017) did not suggest a "partially marine ecology" for Halszkaraptor, and did not 456 suggest a plesiosaur-like locomotory style or a plesiosaur-like forefin morphology in 457 Halszkaraptor, it is unclear why Brownstein (2019) had focused to that peculiar fully-aquatic 458 bauplan. Note that all aquatic and diving birds (both flying and flightless) lack the plesiosaur459 like features in the forelimb listed by Brownstein (2019), so the absence of a plesiosaur-like 460 paddle or a plesiosaur-like swimming style do not necessarily invalidate locomotion in water or a 461 semiaquatic ecology in a maniraptoran theropod. Note that Cau et al. (2017) described the 462 locomotory style of Halszkaraptor using the relatively neuter term "forelimb-assisted 463 swimming" instead of any stronger term that may indicate a peculiar locomotory style more 464 closely analogous to those of, for example, penguins or plesiosaurs. Thus, contra Brownstein 465 (2019), focusing on the absence of fully-aquatic adaptations in Halszkaraptor does not affect the 466 arguments discussed in Cau et al. (2017). Brownstein (2019) suggested that most of the features 
467 forming the unusual body plan of Halszkaraptor are maniraptoriform or maniraptoran

468 plesiomorphies which were subsequently lost along the lineage leading to Eudromaeosauria. As

469 shown above, a significant part of the features listed by Brownstein (2019) in support of that

470 hypothesis are not valid, being based on inaccurate reports not supported by the literature cited

471 therein. In most cases, those statements are based on misinterpretation of the anatomical

472 terminology, or are grounded on problematic homology statements. In the most problematic

473 cases, the mention of those features is merely false, being them absent in the holotype of $H$.

474 escuilliei (e.g., the so-called "dentary chin" is not present in MPC-D 102/109). Once tested

475 quantitatively, the remaining character statements mentioned by Brownstein (2019) are in large

476 part inferred as synapomorphies of the halszkaraptorine lineage or, at most, as synapomorphies

477 of the clade also including the unenlagiines (e.g., Gianechini et al., 2011, Gianechini et al., 2017;

478 Gianechini et al., 2018), and were acquired by that lineage after its divergence from the other

479 dromaeosaurids. Contra Brownstein (2019), the most parsimonious scenario places the loss of

480 serration in the lateral dentition, the increased number of lateral teeth, the elongation of the neck,

481 and the development of the prominent supratrochanteric shelf, as novelties acquired along the

482 "halszkaraptorine-unenlagiine" lineage: all these features were not inherited from

483 maniraptoriform ancestors, and were not secondarily lost in eudromaeosaurs. The majority of the

484 similarities with some maniraptoriforms are homoplastic convergences (a phenomenon

485 widespread among theropod dinosaurs, see Holtz, 2001). At least seven of the halszkaraptorine

486 novelties are convergently acquired by spinosaurids, and are integrated in a semiacquatic and

487 piscivorous ecology (Charig and Milner, 1997; Ibrahim et al., 2014; Cau et al., 2017; Table 1).

488 One of these features, reported here for the first time, is the "festooning pattern" in the upper

489 dentition size variation, which recalls semi-aquatic crocodilians (see Charig and Milner, 1997;

490 Dal Sasso et al., 2005; Pol et al., 2009). In Halszkaraptor, the anteriormost two maxillary teeth

491 (and corresponding alveoli) are smaller and much slender than the other anterior maxillary teeth

492 and also smaller than the largest premaxillary teeth: this condition produces a distinct sinusoidal

493 ("festooning") oral margin due to the presence of two zones bearing elongate fang-like teeth, one

494 in the premaxilla and one in the anterior half of the maxilla, separated by a zone bearing reduced

495 teeth (Figure 3). This condition is markedly different from the straight and uniform cutting

496 surface present in the oral margin of the herbivorous theropods (Zanno \& Makovicky, 2011; see

497 Figure 1A), and has been interpreted as an adaptation for foraging efficiently in aquatic 
498 environments and for grabbing evasive prey items (Vullo et al., 2016). This snout morphology is

499 frequently associated with the presence of numerous neurovascular pits opening on most of the

500 premaxillary surface (Vullo et al., 2016), which is also shared by H. escuilliei and spinosaurids.

501 Assuming that the peculiar halszkaraptorine features are maniraptoriform plesiomorphies (as

502 claimed in Brownstein, 2019) is not the most parsimonious explanation of the evidence, because

503 it would require the secondary loss of all these claimed ancestral states in oviraptorosaurs, in the

504 "avialan-troodontid" lineage (Averaptora) and in the "eudromaeosaur-microraptorine" lineage.

505 The scenario supported here confirms the hypothesis that, during their evolution, different

506 coelurosaurian lineages converged to a non-ziphodont, multitoothed, and long-necked body plan

507 independently each other (Zanno \& Makovicky, 2011; Choiniere et al., 2014). It is noteworthy

508 that the result of the current study is obtained setting ambiguous character optimization to favor

509 reversals over convergences (accelerated transformation optimization), and thus endorsing a

510 possible "deep" (maniraptoriform) origin of the halszkaraptorine features and their later reversal

511 among eudromaeosaurs (as suggested by Brownstein, 2019): even with that optimization, the

512 majority of the discussed features are recovered as synapomorphies of the halszkaraptorine

513 lineage, and cannot be interpreted as maniraptoriform plesiomorphies (contra Brownstein, 2019).

514 Brownstein (2019) consistently re-interpreted most of the features of Halszkaraptor listed by

515 Cau et al. (2019) as plesiomorphic conditions of clades more inclusive than Halszkaraptorinae:

516 careful comparison of the terms used in the two papers shows that the character descriptions used

517 by Brownstein (2019) differ from those in Cau et al. (2017) in not distinguishing neomorphic and

518 transformational character statements (Sereno, 2007). For example, Brownstein (2019) did focus

519 on the presence of the supratrochanteric process of the ilium (a neomorphic character state

520 shared by many paravians and therizinosauroids) to challenge Cau et al. (2017), whereas the

521 latter did discuss the development of the shelf-like supratrochanteric process (a transformational

522 character state present uniquely among the halszkaraptorine-unenlagiine lineage). As a

523 consequence of such misinterpretation, what is a genuine apomorphy of the halszkaraptorines is

524 erroneously claimed to be a maniraptoran plesiomorphy. Similarly, Brownstein (2019) did focus

525 on the presence of the interpostzygapophyseal lamina in the cervical vertebrae (a neomorphic

526 character state widespread among maniraptoriforms), whereas Cau et al. (2017) did discuss the

527 development of the expanded and fan-shaped interpostzygapophyseal lamina in the cervical

528 vertebrae (a transformational character state autapomorphic of $H$. escuilliei): the plesiomorphic 
529 status of the neomorphic state does not invalidate the autapomorphic status of the

530 transformational one. It should be remarked that Brownstein's (2019) scenario failed to provide

531 an evolutionary explanation for the autapomorphic features that even the latter paper recognizes

532 as being present in Halszkaraptor. The mere assertion of a "transitional" morphology in

533 Halszkaraptor does not provide an explanation for its autapomorphies, because the latter, by

534 definition, are not states intermediate between non-dromaeosaurids and later-diverging

535 dromaeosaurids, but are instead novel features acquired uniquely along the terminal branch. All

536 these features are unexplained under Brownstein's (2019) scenario, because they are not

537 maniraptoran plesiomorphies and are not correlated to an herbivorous/omnivorous ecology (see

538 Zanno and Makovichy, 2011). Given that these features are observed among piscivorous and

539 aquatic amniotes, as discussed by Cau et al. (2017), and in absence of an alternative explanation

540 for their presence in Halszkaraptor, the ecomorphological hypothesis discussed by the latter

541 study keeps being valid even under the revised phylogenetic framework advocated by

542 Brownstein (2019). Paradoxically, the sister-taxon relationship between Halszkaraptorinae and

543 Unenlagiinae suggested by Brownstein (2019) (but see it discussed also in Cau, 2018; Gianechini

544 et al., 2018; and Hartman et al., 2019), weakens the so-claimed "transitional" status for the

545 morphology present in Halszkaraptor, because it removes the latter taxon from a more direct

546 basal divergence near the ancestral dromaeosaurid node, and places it nested among a disparate

547 branch of non-eudromaeosaurian dromaeosaurids (Novas et al., 2009; Gianechini et al., 2018).

548 Furthermore, the amount of morphological divergence of the halszkaraptorines from the

549 ancestral paravian root is comparable to those of microraptorines and velociraptorines (Figure

550 7B): asserting that Halszkaraptor is "likely representative of the morphological transition from

551 the ancestral body plan of maniraptorans to the one [sic] that characterized dromaeosaurids"

552 (Brownstein, 2019) is thus unjustified. In sum, even under the phylogenetic framework

553 advocated by Brownstein (2019), there is no reason for assuming that the disparate morphologies

554 represented by Halszkaraptor and the unenlagiines were "plesiomorphic" or "transitional"

555 between the basal maniraptoran bauplan and other dromaeosaurids. The evolutionary scenario

556 suggested by Brownstein (2019) is thus falsified by its own phylogenetic structure.

557

558 CONCLUSIONS

559 The hypothesis that the body plan of Halszkaraptor represents a "transitional" condition 
560 intermediate between non-paravian maniraptoriforms and eudromaeosaurians is based on a series

561 of non-rigorous homology hypotheses, on the misinterpretation of several character statements

562 describing the coelurosaurian diversity, and has been erected over a problematic list of literature

563 misreports and misquotes. Halszkaraptor markedly diverged from the other maniraptorans, and

564 careful investigation of the character state distribution among coelurosaurs confirms that the

565 large majority of the peculiar features of $H$. escuilliei are not maniraptoran symplesiomorphies,

566 and cannot define the ancestral dromaeosaurid body plan. A quantitative analysis of the

567 morphological divergence among these taxa falsifies Brownstein's (2019) scenario, dismissing a

568 "transitional" status for the halszkaraptorines relative to other dromaeosaurids. Furthermore, that

569 hypothesis is unable to interpret the peculiarities of the halszkaraptorines which are absent in the

570 herbivorous/omnivorous maniraptoriforms, and fails to explain the similarities between

571 Halszkaraptor, semiaquatic birds and piscivorous reptiles.

572

573 Acknowledgments

574 I thank P. Godefroit for access to MPC D-102/109, and to V. Beyrand, P. Tafforeau and D.

575 Voeten for rendering of scan data. I thank L. Zanno for the helpful information on the anatomical

576 terminology, S. Lautenschlager for providing digital rendering images of MPC D-100/111, and

577 to D. Iurino for providing digital rendering images of MSNM V4047. I thank Academic Editor F.

578 Knoll, F. Agnolin, C. Brownstein and D. Hone for the revision of the first draft of this

579 manuscript. The program TNT is being made available with the sponsorship of the Willi Hennig

580 Society.

581

582 References

583 Agnolin, F.L., Motta, M.J., Brissón Egli, F., Lo Coco, G., Novas. F.E. (2018). Paravian

584 phylogeny and the dinosaur-bird transition: an overview. Frontiers in Earth Sciences

585 https://doi.org/10.3389/feart.2018.00252

586 Balanoff, A.M. \& Norell, M.A. (2012). Osteology of Khaan mckennai (Oviraptorosauria:

587 Theropoda). American Museum of Natural History Bulletin 372: 1-77.

588 Balanoff, A.M., Xu, X., Kobayashi, Y., Matsufune, Y. \& Norell, M. (2009). Cranial Osteology

589 of the Theropod Dinosaur Incisivosaurus gauthieri (Theropoda: Oviraptorosauria).

$590 \quad$ American Museum Novitates 3651: 1-35.

Peer] reviewing PDF | (2019:12:43616:1:1:REVIEW 10 Jan 2020) 
591 Browsntein, C.D. (2019). Halszkaraptor escuilliei and the evolution of the paravian bauplan.

592 Scientific Reports 9:16455. https://doi.org/10.1038/s41598-019-52867-2

593 Brusatte, S.L. \& Sereno, P.C. (2007). A new species of Carcharodontosaurus (Dinosauria:

594 Theropoda) from the Cenomanian of Niger and a revision of the genus. Journal of

595 Vertebrate Paleontology 27(4): 902-916.

596 Brusatte S., Lloyd G.,Wang S., \& Norell M. (2014). Gradual assembly of avian body plan

597 culminated in rapid rates of evolution across the dinosaur-bird transition. Current Biology 598 24(20): 2386-2392.

599 Carpenter, K., Sanders, F., Reed, B., Reed, J. \& Larson, P. (2010). Plesiosaur swimming as

600 interpreted from skeletal analysis and experimental results. Transactions of the Kansas

$601 \quad$ Academy of Sciences 113: 1-34 (2010).

602 Cau, A. (2018). The assembly of the avian body plan: a 160-million-year long process. Bollettino 603 della Società Paleontologica Italiana 57(1): 1-25.

604 Cau A., Beyrand V., Voeten D.F.A.E., Fernandez V., Tafforeau P., Stein K., Barsbold R., 605 Tsogtbaatar K., Currie P.J., \& Godefroit P. (2017). Synchrotron scanning reveals 606 amphibious ecomorphology in a new clade of bird-like dinosaurs. Nature 552: 395-399.

607 Cau, A., Brougham, T. \& Naish, D. (2015). The phylogenetic affinities of the bizarre Late 608 Cretaceous Romanian theropod Balaur bondoc (Dinosauria, Maniraptora): dromaeosaurid 609 or flightless bird? PeerJ 3, e1032.

610 Cau, A., Madzia, D. (2018). Redescription and affinities of Hulsanpes perlei (Dinosauria, 611 Theropoda) from the Upper Cretaceous of Mongolia. PeerJ 6:e4868; DOI $612 \quad 10.7717$ peerj.4868.

613 Charig, A.J. \& Milner, A.C. (1997). Baryonyx walkeri, a fish-eating dinosaur from the Wealden 614 of Surrey. Natural History Museum of London Bulletin 53: 11-70.

615 Chiappe, L.M., Norell, M.A. \& Clark, J.M. (1998). The skull of a relative of the stem-group bird $616 \quad$ Mononykus. Nature 392(6673): 275-278.

617 Choiniere, J.N., Clark, J.M., Forster, C.M., Norell, M.A., Eberth, D.A., Erickson, G.M., Chu H. $618 \& \mathrm{Xu}, \mathrm{X}$. (2010). A juvenile specimen of a new coelurosaur (Dinosauria: Theropoda) from 619 the Middle-Late Jurassic Shishugou Formation of Xinjiang, People's Republic of China. 620 Journal of Systematic Palaeontology 12(2): 177-215.

621 Choiniere, J.N., Clark, J.M., Norell, M. \& Xu, X. (2014). Cranial osteology of Haplocheirus 
622

623

624

625

626

627

628

629

630

631

632

633

634

635

636

637

638

639

640

641

642

643

644

645

646

647

648

649

650

651

652

sollers Choiniere et al. 2010 (Theropoda, Alvarezsauroidea). American Museum Novitates 3816: $1-44$.

Choiniere, J.N., Forster, C.A. \& de Klerk, W.J. (2012). New information on Nqwebasaurus thwazi, a coelurosaurian theropod from the Early Cretaceous Kirkwood Formation in South Africa. Journal of African Earth Sciences 71-72: 1-17.

Clark, B.D. \& Bemis, W. (1979). Kinematics of swimming of penguins at the Detroit Zoo, Journal of Zoology, London 188: 411-428.

Combes, S.A. \& Daniel, T.L. (2001). Shape, flapping and flexion: wing and fin design for forward flight. Journal of Experimental Biology 204: 2073-2085.

Dal Sasso, C., Maganuco, S., Buffetaut, E., Mendez, M.A. (2005). New information on the skull of the enigmatic theropod Spinosaurus, with remarks on its size and affinities. Journal of Vertebrate Paleontology 25(4): 888-896.

Dingus, L., D.B. Loope, D. Dashzeveg, C.C. Swisher III, C. Minjin, M.J. Novacek, and M.A. Norell. (2008). The Geology of Ukhaa Tolgod (Djadokhta Formation, Upper Cretaceous, Nemegt Basin, Mongolia). American Museum Novitates 3616: 1-40.

Gianechini, F.A. \& Apesteguia, S. (2011). Unenlagiinae revisited: dromaeosaurid theropods from South America. Anais da Academia Brasileira de Ciencias 83(1): 163-195.

Gianechini, F.A., Makovicky, P.J. \& Apesteguía, S. (2011). The teeth of the unenlagiine theropod Buitreraptor from the Cretaceous of Patagonia, Argentina, and the unusual dentition of the Gondwanan dromaeosaurids. Acta Palaeontologica Polonica 56(2): 279290.

Gianechini, F.A., Makovicky, P.J. \& Apesteguía, S. (2017). The cranial osteology of Buitreraptor gonzalezorum Makovicky, Apesteguía, and Agnolín, 2005 (Theropoda, Dromaeosauridae), from the Late Cretaceous of Patagonia, Argentina. Journal of Vertebrate Paleontology 37(1): e1255639.

Gianechini, F.A., Makovicky, P.J., Apesteguía, S. \& Cerda, I. (2018). Postcranial skeletal anatomy of the holotype and referred specimens of Buitreraptor gonzalezorum Makovicky, Apesteguía and Agnolín 2005 (Theropoda, Dromaeosauridae), from the Late Cretaceous of Patagonia. PeerJ 6, e4558.

Godefroit, P., Cau, A., Dong-Yu, H., Escuillie, F., Wenhao, W., Dyke, G. (2013b). A Jurassic avialan dinosaur from China resolves the early phylogenetic history of birds. Nature 
653

654

655

656

657

658

659

660

661

662

663

664

665

666

667

668

669

670

671

672

673

674

675

676

677

678

679

680

681

682

683

498(7454): 359-362.

Godefroit, P., Demuynck, H., Dyke, G.J., Hu, D., Escuillié, F. \& Claeys, P. (2013a). Reduced plumage and flight ability of a new Jurassic paravian theropod from China. Nature Communications 4, article 1394.

Goloboff, P., Farris, J., \& Nixon, K. (2008). TNT, a free program for phylogenetic analysis. Cladistics 24: 774-786.

Hartman, S., Mortimer, M., Wahl, W.R, Lomax, D.R, Lippincott, J., Lovelace, D.M. (2019). A new paravian dinosaur from the Late Jurassic of North America supports a late acquisition of avian flight. PeerJ 7:e7247 DOI 10.7717/peerj.7247.Hinić-Frlog, S. \& Motani, R. (2010). Relationship between osteology and aquatic locomotion in birds: determining modes of locomotion in extinct Ornithurae. Journal of Evolutionary Biology 23: 372- 385 (2010).

Holtz, T.R., Jr. (2001). Arctometatarsalia Revisited: The Problem of Homoplasy in Reconstructing Theropod Phylogeny. In Gauthier J. \& Gall L.F. (eds), New Perspectives on the Origin and Early Evolution of Birds, Proceedings of the International Symposium in Honor of John H. Ostrom: 99-122.

Hone, D.W.E. and Holtz, T.R.,Jr. (2017). A Century of Spinosaurs - A Review and Revision of the Spinosauridae with Comments on Their Ecology. Acta Geologica Sinica 91: 11201132.

Hu, D., Hou, L., Zhang, L. \& Xu, X. (2009). A pre-Archaeopteryx troodontid theropod from China with long feathers on the metatarsus. Nature 461:640-643.

Hwang, S.H, Norell, M.A, Qiang, J., Keqin, G. (2002). New specimens of Microraptor zhaoianus (Theropoda: Dromaeosauridae) from northeastern China. American Museum Novitates 3381:1-44.

Ibrahim, N., Sereno, P.C., Dal Sasso, C., Maganuco, S., Fabbri, M., Martill, D.M., Zouhri, S., Myhrvold, N. \& Iurino, D.A. (2014). Semiaquatic adaptations in a giant predatory dinosaur. Science 345(6204): 1613-1616.

Ji, Q., Norell, M.A., Makovicky, P. J., Gao, K., Ji, S. \& Yuan, C. (2003). An Early Ostrich Dinosaur and Implications for Ornithomimosaur Phylogeny. American Museum Novitates 3420: 1-19.

Kear, J., and Hulme, M. (2005). Ducks, geese and swans. Volume 2, Species accounts (Cairina 
684

685

686

687

688

689

690

691

692

693

694

695

696

697

698

699

700

701

702

703

704

705

706

707

708

709

710

711

712

713

714

to Mergus). Oxford : Oxford University Press, Oxford, pp. 930.

Kobayashi, Y. \& Lü, J.-C. (2003). A new ornithomimid dinosaur with gregarious habits from the Late Cretaceous of China. Acta Palaeontologica Polonica 48 (2): 235-259.

Kobayashi, Y. \& Barsbold, R. (2005). Reexamination of a primitive ornithomimosaur, Garudimimus brevipes Barsbold, 1981 (Dinosauria:Theropoda), from the Late Cretaceous of Mongolia. Canadian Journal of Earth Sciences 42(9): 1501-1521.

Ksepka, D.T. \& Norell, M.A. (2004). Ornithomimosaur Cranial Material from Ukhaa Tolgod (Omnogov, Mongolia). American Museum Novitates 3448: 1-4.

Langston, W., Jr. (1975). Ziphodont crocodiles: Pristichampsus vorax (Troxell), new comb., from the Eocene of North America. Fieldiana (Geology) 33: 291-314.

Lautenschlager, S., Witmer, L.M., Altangerel, P., Zanno, L.E. \& Rayfield, E.J. (2014). Cranial anatomy of Erlikosaurus andrewsi (Dinosauria: Therizinosauria): new insights based on digital reconstruction. Journal of Vertebrate Paleontology 34(6): 1263-1291.

Lee, Y.N., Barsbold, R., Currie, P.J., Kobayashi, Y., Lee, H.J., Godefroit, P., Escuillié, F.O. \& Chinzorig, T. (2014). Resolving the long-standing enigmas of a giant ornithomimosaur Deinocheirus mirificus. Nature 515(7526): 257-260.

Lefeld, J. (1971). Geology of the Djadokhta Formation at Bayn Dzak (Mongolia). In Z. KielanJaworowska (editor), Results of the Polish-Mongolian Palaeontological Expeditions. Part III. Palaeontologia Polonica 25: 101-127.

Lefèvre, U., Cau, A., Cincotta, A., Hu, D., Chinsamy, A., Escuillié, F. \& Godefroit, P. (2017). A new Jurassic theropod from China documents a transitional step in the macrostructure of feathers. The Science of Nature 104:74(1-13).

Lü, J.-C., Xu, L., Liu, Y.-Q., Zhang, X.-L., Jia, S.H. \& Ji, Q. (2010). A new troodontid theropod from the Late Cretaceous of central China, and the radiation of Asian troodontids. Acta Palaeontologica Polonica 55 (3): 381-388.

Milner, A.C. (2003). Fish-eating theropods: a short review of the systematics, biology and palaeobiology of spinosaurs. Journadas Internacionales sobre paleontologia de Dinosaurios y su Entoro 2: 129-138.

Nilsson, L. (1972). Habitat Selection, Food Choice, and Feeding Habits of Diving Ducks in Coastal Waters of South Sweden during the Non-Breeding Season. Ornis Scandinavica 3: $55-78$.

PeerJ reviewing PDF | (2019:12:43616:1:1:REVIEW 10 Jan 2020) 
715 Novas, F.E., Pol, D., Canale, J.I., Porfiri, J.D. and Calvo, J.O.(2009). A bizarre Cretaceous

716 theropod dinosaur from Patagonia and the evolution of Gondwanan dromaeosaurids.

717 Proceedings of the Royal Society B 276: 1101-1007.

718 Osmólska, H., Roniewicz, E. \& Barsbold, R. (1972). A new dinosaur, Gallimimus bullatus $\mathrm{n}$. gen., n. sp. (Ornithomimidae) from the Upper Cretaceous of Mongolia. Acta Palaeontologica Polonica 27: 103-143.

Ostrom, J.H. (1969). Osteology of Deinonychus antirrhopus, an unusual theropod dinosaur from the Lower Cretaceous of Montana. Peabody Museum of Natural History Bulletin 30: 1165.

Pei, R., Li, Q., Meng, Q., Gao, K.-Q., \& Norell, M.A. (2014). A New Specimen of Microraptor (Theropoda: Dromaeosauridae) from the Lower Cretaceous of Western Liaoning, China. American Museum Novitates 3821: 1-28.

728

729

730

731

732

733

734

735

736

Perez-Moreno, B.P., Sanz, J.L., Buscalioni, A.D., Moratalla, J.J., Ortega, F. \& Raskin-Gutman, D. (1994). A unique multitoothed ornithomimosaur dinosaur from the Lower Cretaceous of Spain. Nature 370: 363-367.

Pol, D., Turner, A.H., Norell, M.A. (2009). Morphology of the Late Cretaceous crocodylomorph Shamosuchus djadokhtaensis and a discussion of neosuchian phylogeny as related to the origin of Eusuchia. American Museum Novitates 324: 1-103.

Rayfield, E.J., Milner, A.C., Xuan, V.B., \& Young P.G. (2007). Functional morphology of spinosaur "crocodile-mimic" dinosaurs. Journal of Vertebrate Paleontology 27: 892-901.

Richardson, F. (1939). Functional Aspects of the Pneumatic System of the California Brown Pelican. The Condor 41(1): 13-17.

Sereno, P.C. (2007). Logical basis for morphological characters in phylogenetics. Cladistics 23: $565-587$.

Sereno, P.C., Beck, A.L., Dutheil, D.B., Gado, B., Larsson, H.C.E., Lyon, G.H., Marcot, J.D., Rauhut, O.W.M., Sadleir, R.W., Sidor, C.A., Varricchio, D.D., Wilson, G.P. \& Wilson, J.A.(1998). A long-snouted predatory dinosaur from Africa and the evolution of spinosaurids. Science 282(5392): 1298-1302.

Simons, E.L.R. \& O'Connor, P.M. (2012). Bone Laminarity in the Avian Forelimb Skeleton and Its Relationship to Flight Mode: Testing Functional Interpretations. The Anatomical Record 295: 386-396. 
746 Simpson, G.G. (1946). Fossil penguins. Bulletin of the American Museum of Natural History 87:

747

748

749

750

751

752

753

754

755

756

757

758

759

760

761

762

763

764

765

766

767

768

769

770

771

772

773

774

775

776 1-104.

Swofford D. L. (2002). PAUP*. Phylogenetic Analysis Using Parsimony (*and Other Methods). Version 4. Sinauer Associates, Sunderland, Massachusetts.

Turner, A.H., Makovicky, P.J. \& Norell, M.A. (2012). A review of dromaeosaurid systematics and paravian phylogeny. American Museum of Natural History Bulletin 371: 1-206.

Turner, A.H., Pol, D. \& Norell, M.A. (2011). Anatomy of Mahakala omnogovae (Theropoda: Dromaeosauridae), Tögrögiin Shiree, Mongolia. American Museum Novitates 3722: 1-66. Vullo, R., Allain, R., \& Cavin, L. (2016). Convergent evolution of jaws between spinosaurid dinosaurs and pike conger eels. Acta Palaeontological Polonica 61(4): 825-828.

Walker, W.F. (1973). The locomotor apparatus of Testudines. pp. 1-99 in Gans, C. and Parson, T. (eds.), Biology of the Reptilia, v. 4 Morphology. Academic Press, San Diego, CA.

Wedel, M. 2014. Pelican vertebrae are mostly air. Sauropod Vertebra Picture of the Week, https://svpow.com/2014/07/16/pelican-vertebrae-are-mostly-air/

Wedel, M. 2018. Bisected pelican arm bones of the Oxford Museum of Natural History. Sauropod Vertebra Picture of the Week, https://svpow.com/2018/03/17/bisected-pelicanarm-bones-of-the-oxford-museum-of-natural-history/

Xing, L., Persons W.S. IV, Bell, P.R., Xu, X., Zhang, J., Miyashita, T., Wang, F. \& Currie, P.J. (2013). Piscivory in the feathered dinosaur Microraptor. Evolution 67: 2441-2445.

Xu, X. \& Norell, M.A. (2004). A new troodontid dinosaur from China with avian-like sleeping posture. Nature 431: 838-841.

Zanno, L.E. \& Makovicky, P.J. (2011). Herbivorous ecomorphology and specialization patterns in theropod dinosaur evolution. Proceedings of the National Academy of Sciences of the USA 108: 232-237.

Zanno, L.E., Gillette, D.D., Albright, L.B. \& Titus, A.L. (2009). A new North American therizinosaurid and the role of herbivory in 'predatory' dinosaur evolution. Proceedings of the Royal Society B 276: 3505-3511.

Zanno, L.E. (2010). Osteology of Falcarius utahensis: characterizing the anatomy of basal therizinosaurs. Zoological Journal of the Linnean Society 158: 196-230.

Zhou, Z.H., Wang, X.L., Zhang, F.C. \& Xu, X. (2000). Important features of Caudipteryx evidence from two nearly complete new specimens. Vertebrata PalAsiatica 38: 243-254. 


\section{Figure 1}

Comparison between the skull of the therizinosaurid Erlikosaurus andrewsi (MPC D-100/111: A, C) and the paravian Halszkaraptor escuilliei ( MPC D-102/109: B, D), in left lateral $(A, B)$ and dorsal $(C, D)$ views.

Key differences in snout morphology: prenarial part of premaxilla taller than long (a1) or longer than tall (a2); platyrostral condition produced by perinarial widening (a1) or prenarial flattening (a2); complete loss of premaxillary dentition (c1) or supranumerary premaxillary dentition (c2); maxillary dentition lacking replacement waves (d1), or bearing distinct replacement waves (d2); narial fossa widely overlapping premaxillary oral margin (e1) or narial fossa not overlapping premaxillary oral margin. Scale bars in $\mathrm{mm}$. Figures $\mathrm{A}$ and $\mathrm{C}$ provided by Stephan Lautenschlager (used with permission).
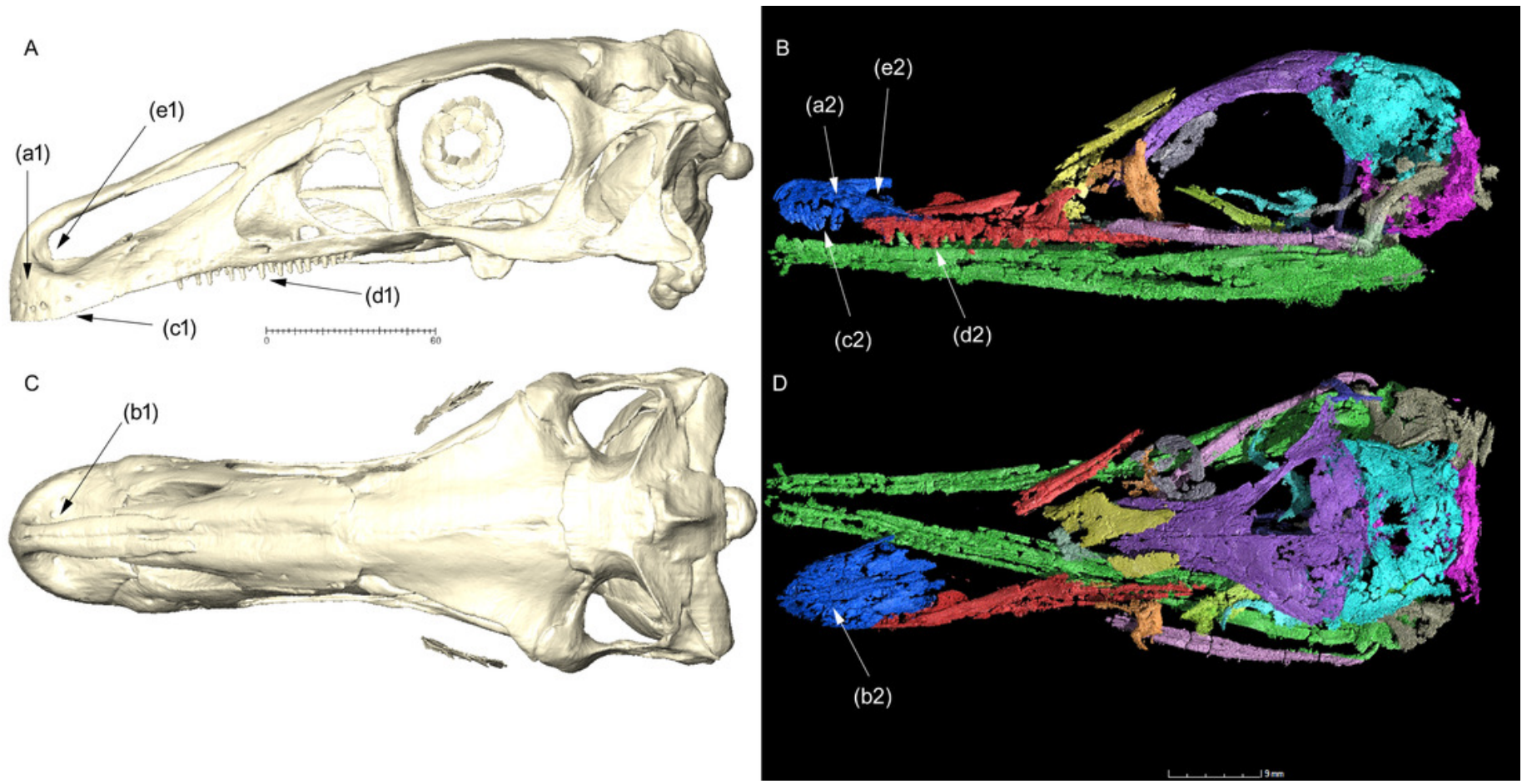


\section{Figure 2}

Development of the premaxillary neurovascular plexus in some archosaurs.

Semitransparent rendering of premaxilla of Erlikosaurus andrewsi (MPC D-100/111: A, B) in lateral (A) and dorsal (B) views. Semitransparent rendering of premaxillae of Halszkaraptor escuilliei ( MPC D-109/109: C, D) in lateral (C ) and dorsal (D) views. Semitransparent rendering of anterior end of snout in Crocodylus sp. (uncatalogued specimen: E), Halszkaraptor escuilliei (F) and Erlikosaurus andrewsi (MPC D-100/111: G) in dorsal view. Semitransparent rendering of snout in cf. Spinosaurus aegyptiacus (MSNM V4047: $\mathrm{H}, \mathrm{I}$ ) in lateral $(\mathrm{H})$ and dorsal (I) views. Figures in (A-D) and (E-I) rescaled at same width for comparison. In red, rendering of the neurovascular plexus. Arrows in E-I indicate the level of the anterior margin of the external naris. Figures $A, B$ and $G$ modified from images provided by Stephan Lautenschlager (used with permission). Figures $\mathrm{H}$, I modified from images provided by Dawid Adam lurino (used with permission). Abbreviations: en, external naris; nps, basal stem of the neurovascular plexus; pnr, prenarial part of premaxilla. 
A

C
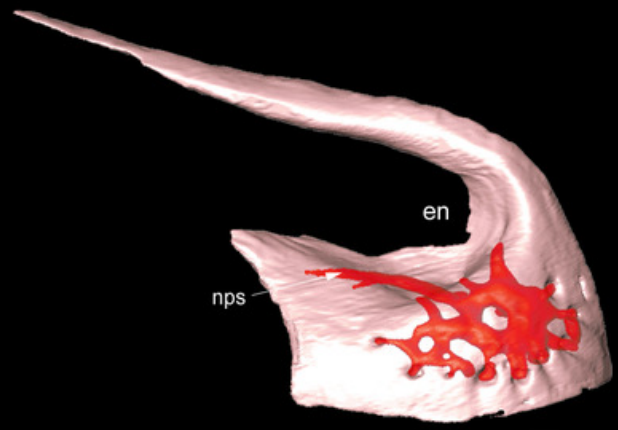

pnr
B

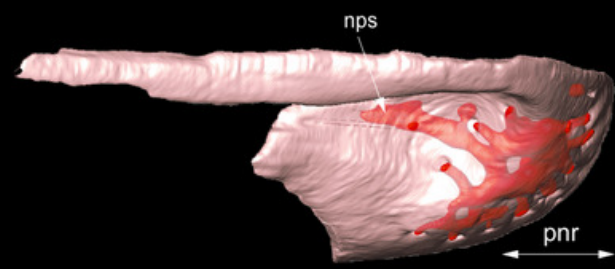

D

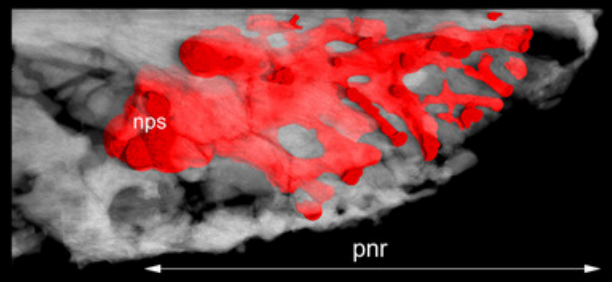

G

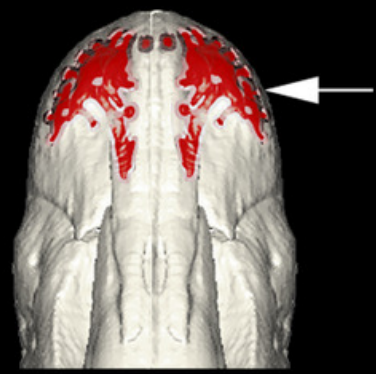

$\mathrm{H}$

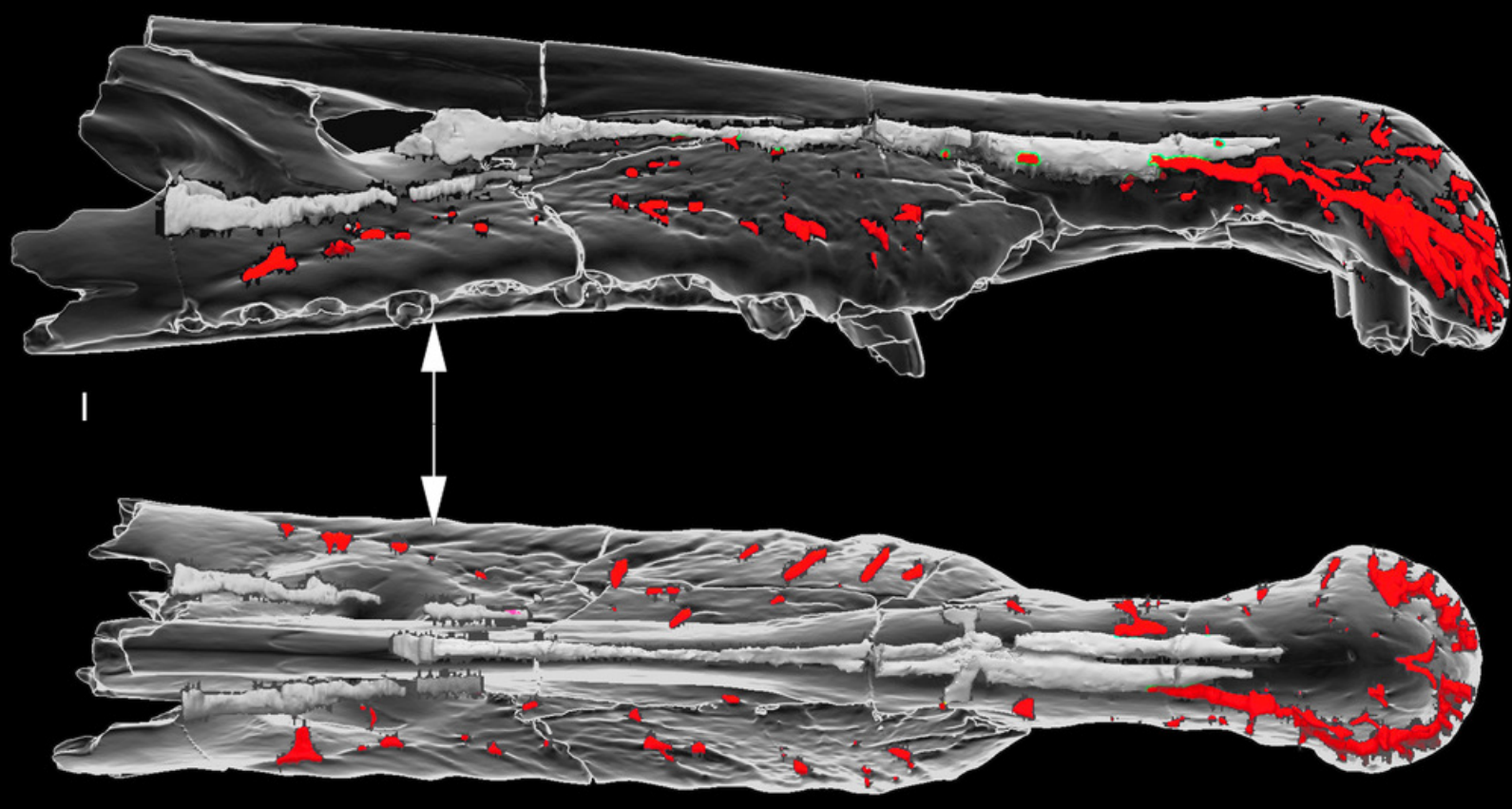




\section{Figure 3}

Premaxillae and maxillae of $H$. escuilliei MPC D-102/109 in right lateral view.

In $\mathrm{A}$, the different bones are colored to help the identification of the distinct elements forming the rostrum. Note that the majority of the right maxilla is lost (light blue), revealing most of the left maxilla (pink) in medial view (in his figure 1, Brownstein, 2019, misinterpreted the preservation of the maxillae and depicted most of the lateral surface of the right maxilla based on the medial side of the left one). In B, semi-transparent reconstruction of the same elements, showing the tooth roots and the "festooning" pattern in tooth size variation. Scale bar in mm. Abbreviations: Imx, left maxilla; Ipmx, left premaxilla; m1-2, first and second maxillary tooth; pdl, paradental lamina; rmx, right maxilla; rpmx, right premaxilla. 


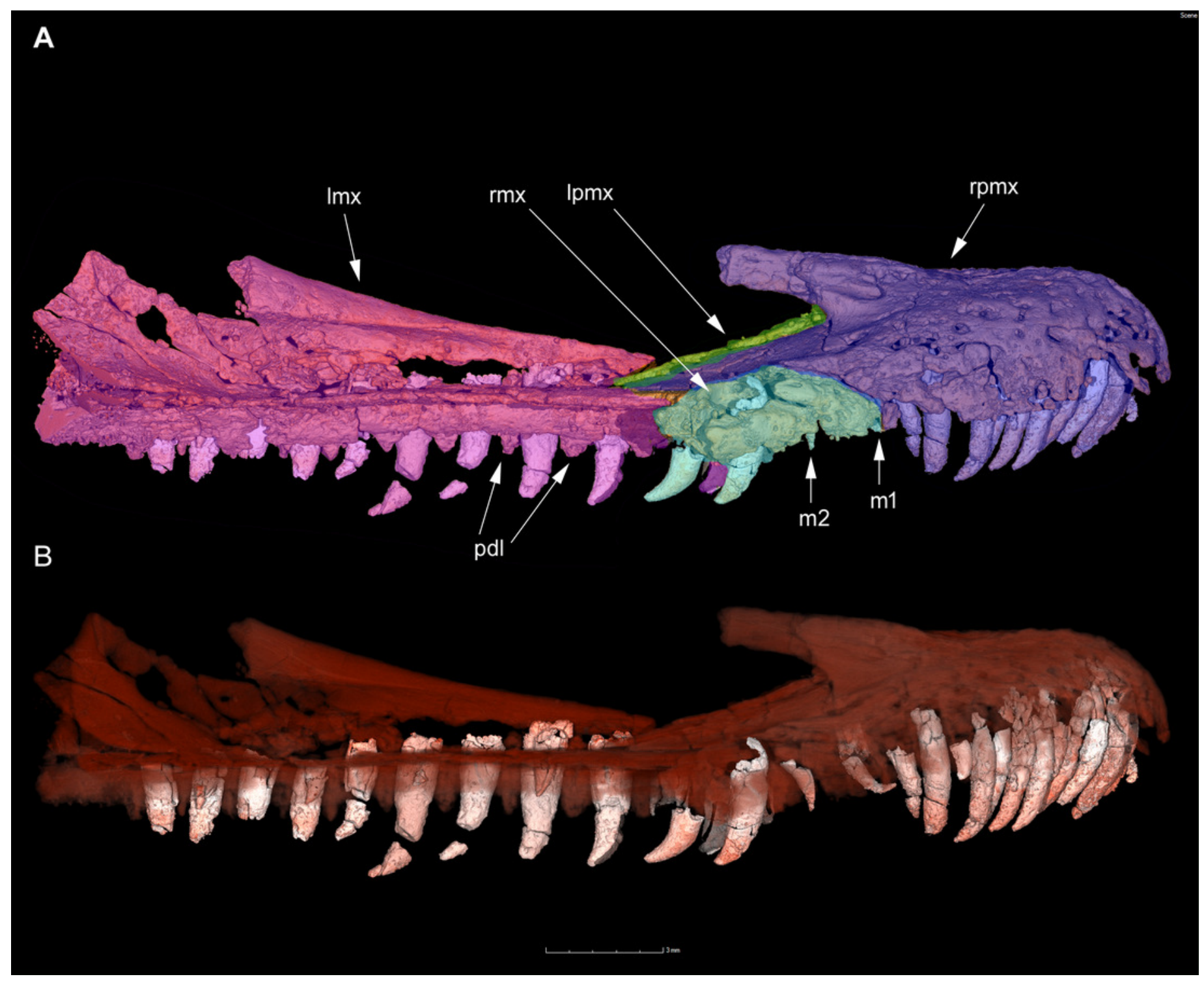


Figure 4

Plot of ulna mid-shaft width relative to ulnar length in theropods.

A, full sample. B, same sample but reduced to non-avian theropods and wing-propelled birds.

Data in Supplementary Files.

A

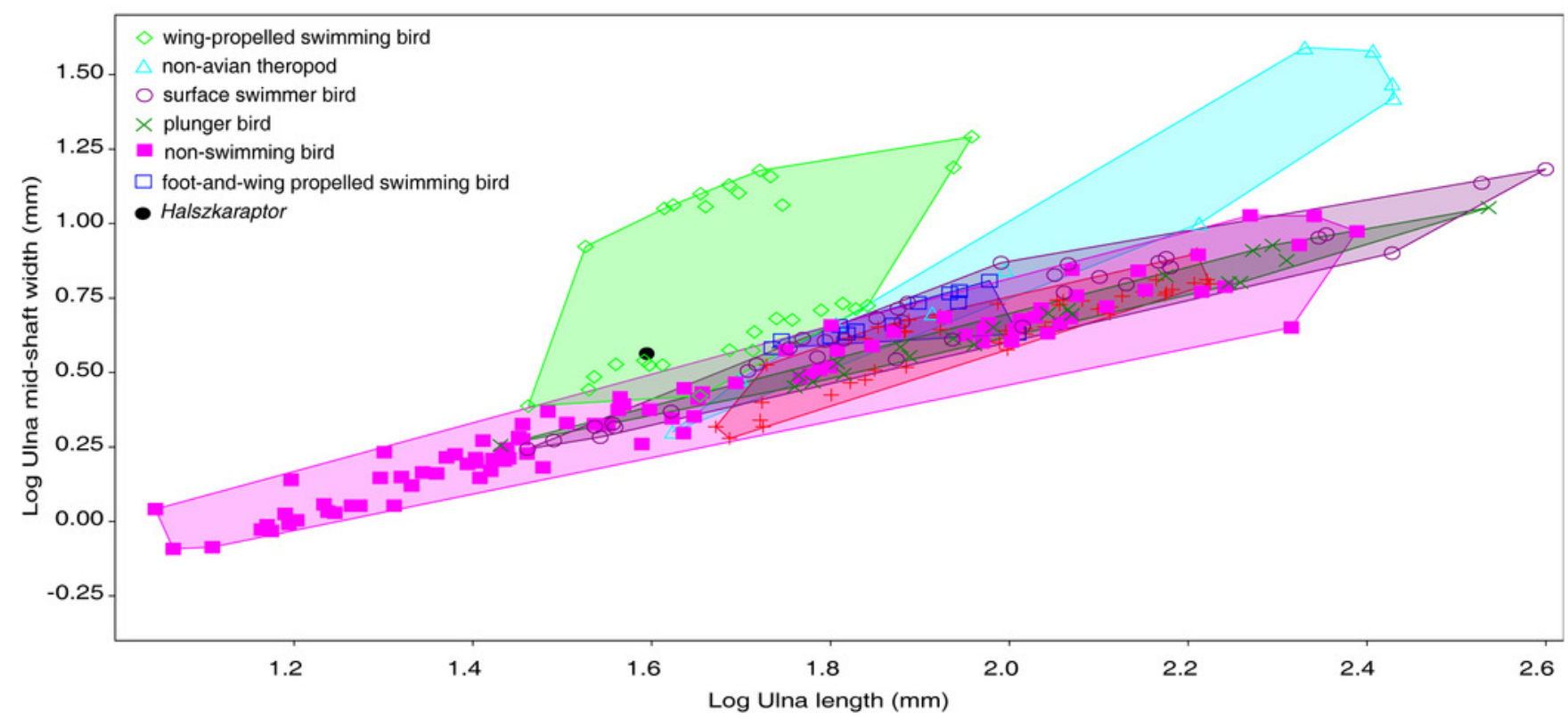

B

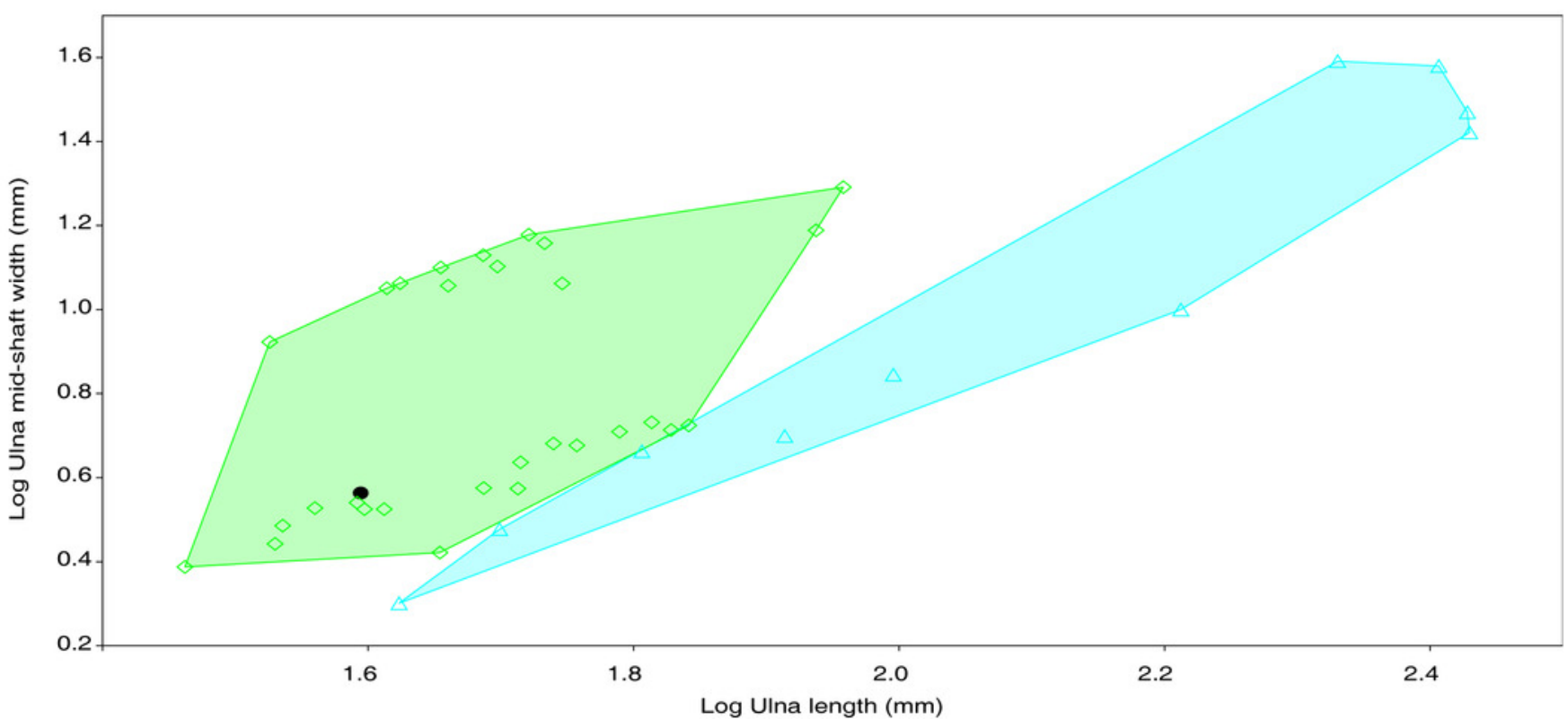


Figure 5

Pedal ungual Il size among paravians.

Plot of pedal ungual II length relative to femur length dismisses Brownstein's (2019) claim that Halszkaraptor's ungual is reduced compared to other dromaeosaurids. Data in Supplementary Files.

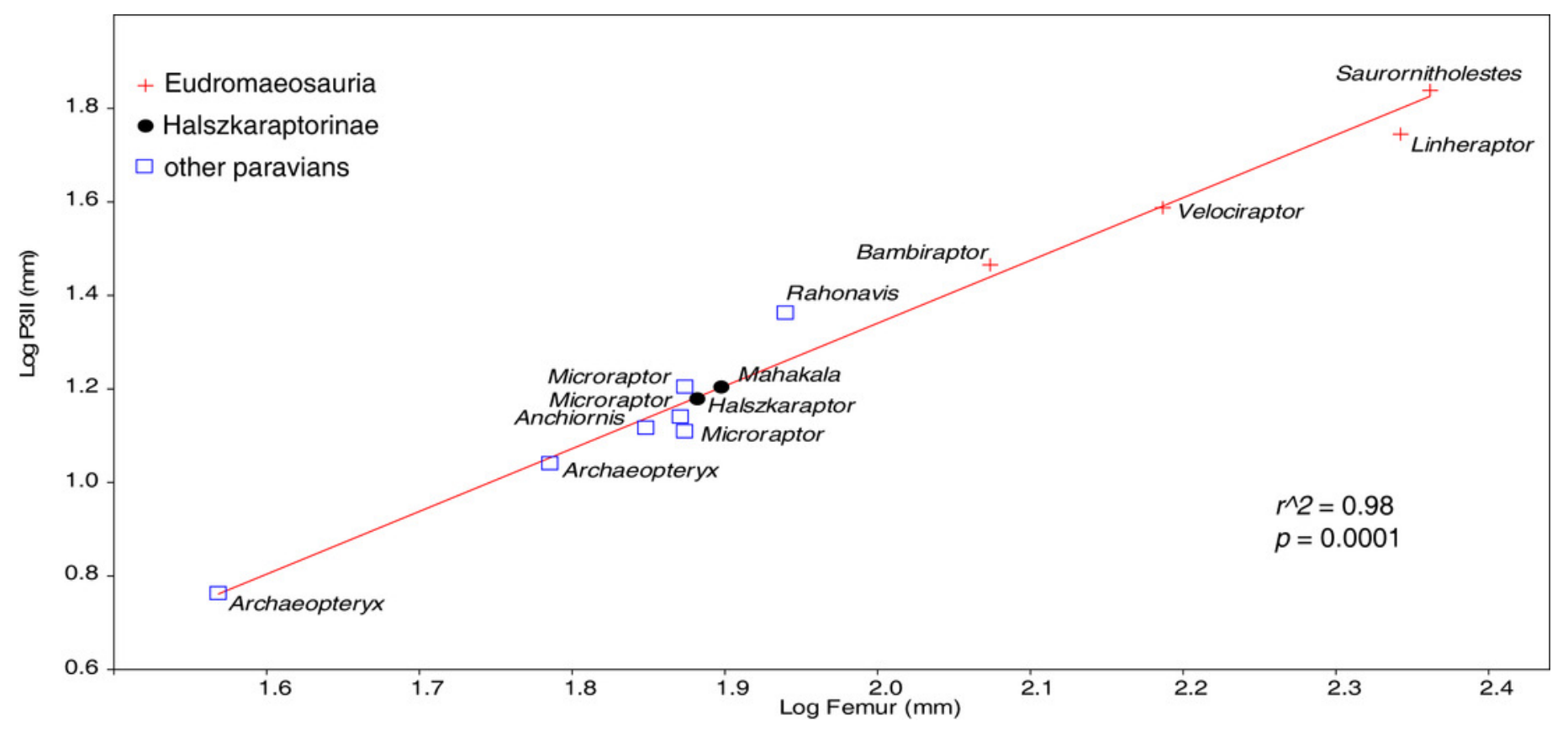




\section{Figure 6}

Development of the supratrochanteric process in the paravian theropods Aurornis xui YFGP-T5198 and Halszkaraptor escuilliei MPC D-102/109.

A, pelvic region of the anchiornithid Aurornis in lateral view. Note that the left ilium is exposed dorsally, showing the thickness of the dorsal margin of the bone. B, pelvic region of $H$. escuilliei, in dorsomedial view. Note the prominent supratrochanteric process which overhangs the lateral surface of the ilium. Scale bars $=30 \mathrm{~mm}$. Abbreviations: li, left ilium; pdm, posterodorsal margin; ri, right ilium. 

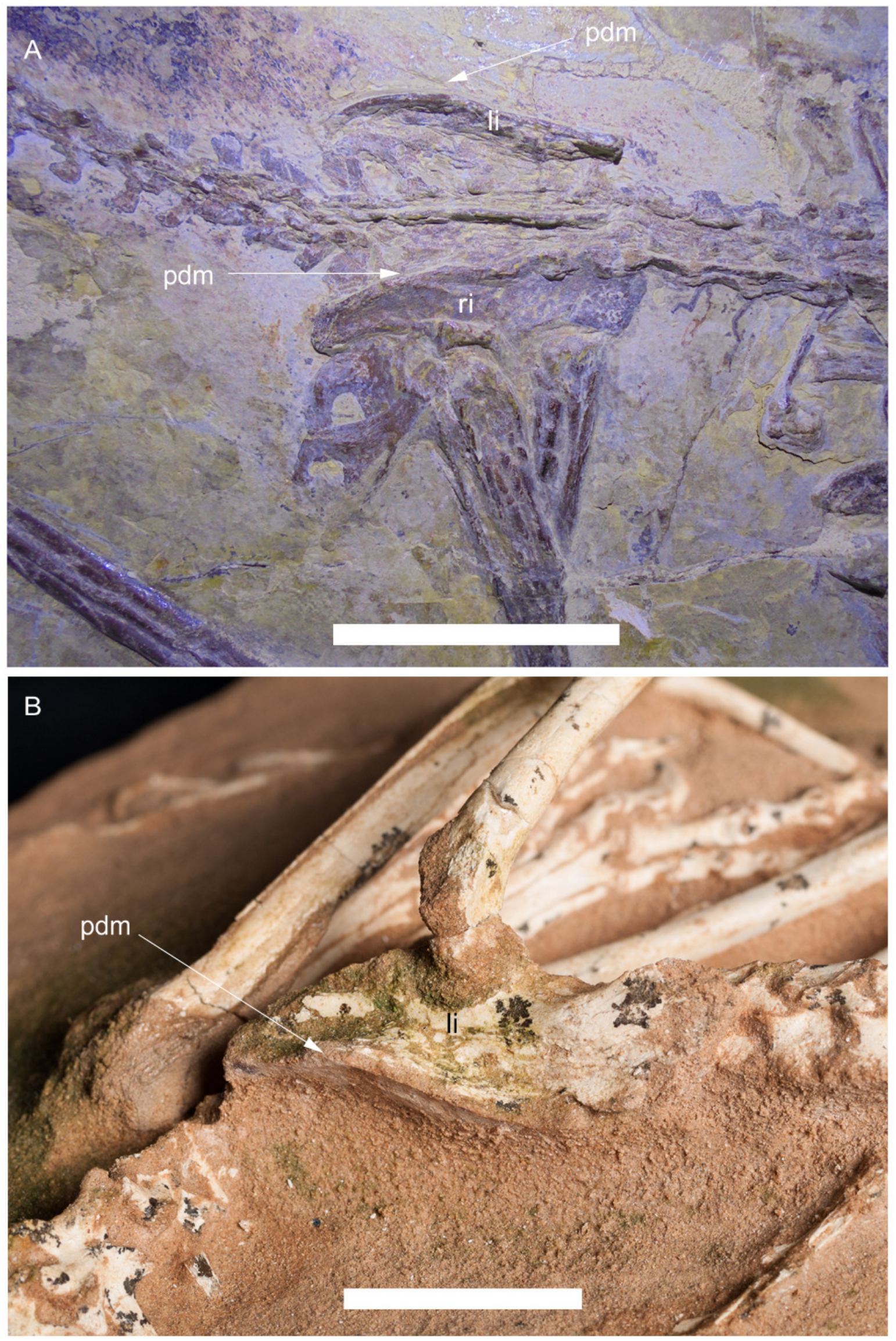


\section{Figure 7}

Phylogeny of the tetanuran theropods focusing on maniraptoriforms.

A, Agreement subtree of 50.000 shortest trees reconstructed by the phylogenetic analysis, used as framework for character state transition optimization. Numbers at branches indicate the morphological features listed in Table 1. B, anagenetic distance (in steps) from the paravian node based on the minimum branch length of the agreement subtree in Figure 7A. 
A
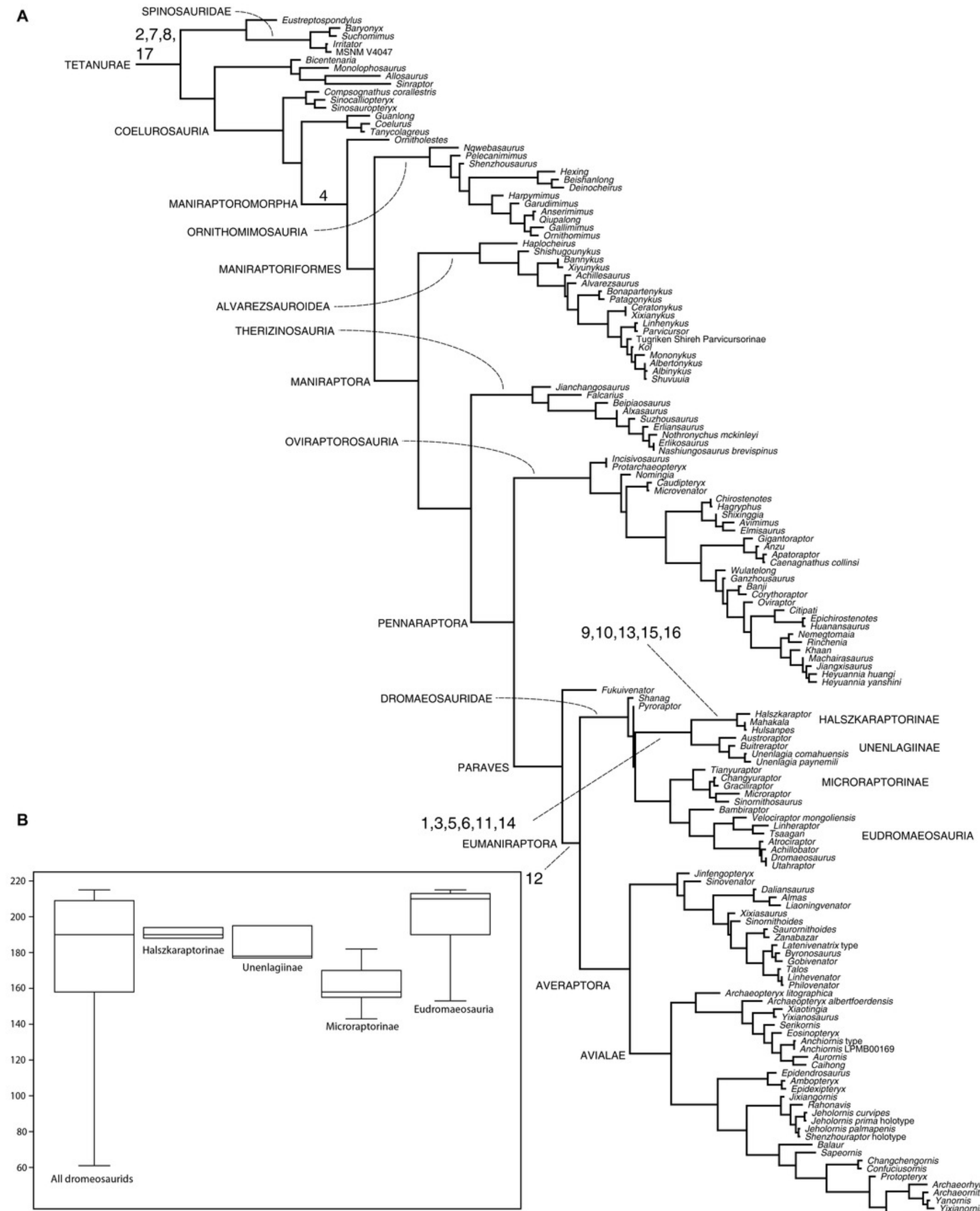

12

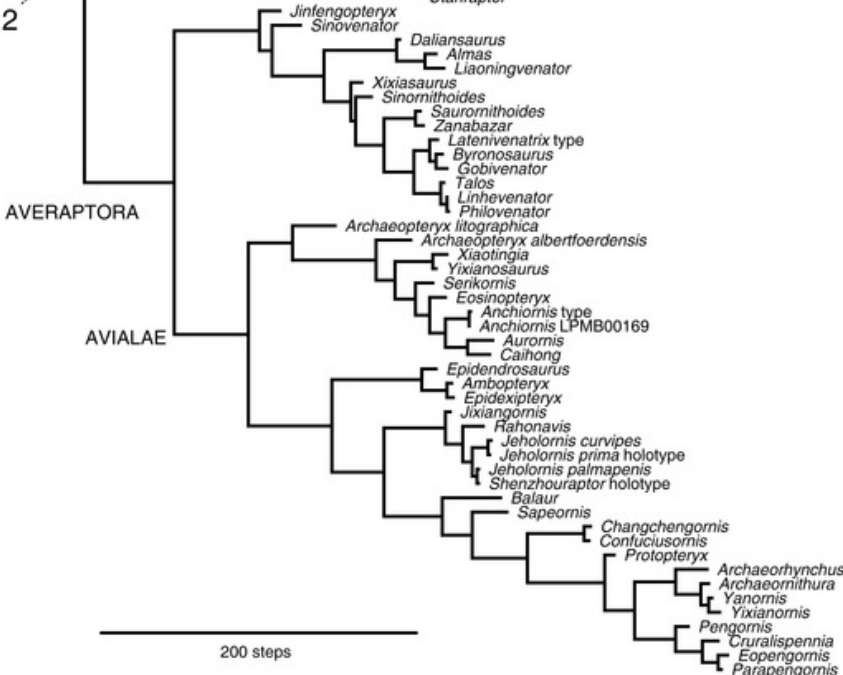




\section{Table $\mathbf{1}$ (on next page)}

Phylogenetic status of 17 key features of Halszkaraptor.

Nodal optimisation of the morphological features of Halszkaraptor body plan, based on the agreement subtree topology. Character numeration refers to the character list of the phylogenetic analysis, with described state indicated by number in brackets. Ambiguously optimized state changes based on accelerated transformation (marked by *). "Novelty" means that the character state in $\mathrm{H}$. escuilliei is optimized as evolving among Halskzaraptorinae or at most among "Halszkaraptorinae + Unenlagiinae" under accelerated transformation optimisation. 


\begin{tabular}{|c|c|c|c|}
\hline $\begin{array}{l}\text { Character statement and Homoplasy } \\
\text { Index (hi) }\end{array}$ & \# char. & Nodes & Status in Halszkaraptor \\
\hline 1) Premaxillae fusion; hi $=0.833$. & $11(1)$ & $\begin{array}{l}\text { "Halszkaraptorinae }+ \\
\text { Unenlagiinae"*. Pygostylia. } \\
\text { Oviraptoroidea. Spinosauridae. }\end{array}$ & $\begin{array}{l}\text { Novelty. Convergent with } \\
\text { pygostylians, oviraptoroids } \\
\text { and spinosaurids. }\end{array}$ \\
\hline $\begin{array}{l}\text { 2) Premaxillary narial margin placed } \\
\text { posterior to mid-lenght of premaxillary } \\
\text { oral margin; hi }=0.941 \text {. }\end{array}$ & $27(1)$ & $\begin{array}{l}\text { Averostra. Lost in: } \\
\text { "Microraptorinae + } \\
\text { Eudromaeosauria"*, } \\
\text { Troodontidae, among } \\
\text { jeholornithids, among } \\
\text { ornithomimosaurs, in } \\
\text { Allosauroidea, in } \\
\text { Tyrannosauroidea. }\end{array}$ & $\begin{array}{l}\text { Averostran plesiomorphy. } \\
\text { Note that Halszkaraptor } \\
\text { shows a novel state: the } \\
\text { narial margin placed more } \\
\text { posterior then the whole } \\
\text { premaxillary body } \\
\text { (convergent with avialans } \\
\text { and spinosaurids). }\end{array}$ \\
\hline $\begin{array}{l}\text { 3) Number of premaxillary teeh }>4 \text {; hi }= \\
0.8 \text {. }\end{array}$ & $14(1)$ & $\begin{array}{l}\text { "Halszkaraptorinae }+ \\
\text { Unenlagiinae"*. } \\
\text { Ornithomimosauria*. } \\
\text { Spinosauridae. }\end{array}$ & $\begin{array}{l}\text { Novelty. Convergent with } \\
\text { basal ornithomimosaurs and } \\
\text { spinosaurids. }\end{array}$ \\
\hline $\begin{array}{l}\text { 4) Premaxillary teeth unserrated; hi }= \\
0.875 .\end{array}$ & $15(1)$ & $\begin{array}{l}\text { Maniraptoromorpha. Homoplastic } \\
\text { in dromaeosaurids and } \\
\text { troodontids. Spinosaurinae. }\end{array}$ & $\begin{array}{l}\text { Maniraptoriform } \\
\text { symplesiomorphy. } \\
\text { Convergent with } \\
\text { spinosaurines. }\end{array}$ \\
\hline 5) Lateral teeth unserrated; hi $=0.917$. & $159(1)$ & $\begin{array}{l}\text { Alvarezsauroids more derived } \\
\text { than Haplocheirus*. } \\
\text { Pannaraptora*. Lost at } \\
\text { Dromaeosauridae root*. Re- } \\
\text { gained in "Halszkaraptorinae + } \\
\text { Unenlagiinae". } \\
\text { Homoplastic in Troodontidae. } \\
\text { Spinosaurinae. }\end{array}$ & $\begin{array}{l}\text { Novelty. Convergent with } \\
\text { non-dromaeosaurid } \\
\text { pennaraptorans and } \\
\text { spinosaurines. }\end{array}$ \\
\hline 6) $>20$ maxillary teeth; $\mathrm{hi}=0.9$. & $34(1)$ & $\begin{array}{l}\text { Maniraptoriformes. Lost in } \\
\text { Pennaraptora. Re-gained in } \\
\text { "Halszkaraptorinae }+ \\
\text { Unenlagiinae". Re-gained in } \\
\text { "Sinovenatorinae + } \\
\text { Troodontinae". Baryonychinae*. }\end{array}$ & $\begin{array}{l}\text { Novelty. Convergent with } \\
\text { non-pennaraptoran } \\
\text { maniraptoriforms and } \\
\text { baryonychines. }\end{array}$ \\
\hline $\begin{array}{l}\text { 7) Premaxillary teeth incisiviform; hi }= \\
0.917 .\end{array}$ & $16(1)$ & $\begin{array}{l}\text { Averostra*. Lost in } \\
\text { Alvarezsauroidea*, Averaptora } \\
\text { and Oviraptoroidea*. Homoplastic } \\
\text { in Eudromaeosauria and } \\
\text { Troodontidae. }\end{array}$ & $\begin{array}{l}\text { Averostran } \\
\text { symplesiomorphy. }\end{array}$ \\
\hline $\begin{array}{l}\text { 8) Lateral teeth labiolingually compressed; } \\
\text { hi }=0.875 \text {. }\end{array}$ & $599(0)$ & Theropoda. Lost in Spinosauridae. & Theropod plesiomorphy. \\
\hline $\begin{array}{l}\text { 9) Cervical vertebrae elongate (centrum } \\
\text { more than twice longer than deep); hi = } \\
0.875 .\end{array}$ & $222(1)$ & $\begin{array}{l}\text { Halszkaraptorinae*. Fukuivenator. } \\
\text { "Caudipterydae + } \\
\text { Oviraptoroidea"*. } \\
\text { Lost in heyuannines*. Falcarius. } \\
\text { "Deinocheiridae + } \\
\text { Ornithomimidae". Spinosauridae. }\end{array}$ & $\begin{array}{l}\text { Novelty. Highly } \\
\text { homoplastic among other } \\
\text { maniraptoriforms. } \\
\text { Convergent with } \\
\text { spinosaurids. }\end{array}$ \\
\hline 10) Horizontally-oriented caudal & $1726(1)$ & Halszkaraptorinae & Novelty. \\
\hline
\end{tabular}




\begin{tabular}{|c|c|c|c|}
\hline zygapophyses; hi $=0$. & & & \\
\hline $\begin{array}{l}\text { 11) Prominent caudal prezygocostal } \\
\text { laminae; } \mathrm{hi}=0.857 \text {. }\end{array}$ & $626(1)$ & $\begin{array}{l}\text { Neotetanurae. Lost in derived } \\
\text { ornithomimosaurs, some } \\
\text { alvarezsauroids, oviraptorids, and } \\
\text { in Eumaniraptora. Re-gained in } \\
\text { "Halszkaraptorinae + } \\
\text { Unenlagiinae". }\end{array}$ & $\begin{array}{l}\text { Novelty. Homoplastic } \\
\text { among other } \\
\text { maniraptoriforms. }\end{array}$ \\
\hline 12) Robust metacarpal III; hi $=0.95$. & $322(0)$ & $\begin{array}{l}\text { Eumaniraptora*. Lost in } \\
\text { "Microraptoria }+ \\
\text { Eudromaeosauria"*. Homoplastic } \\
\text { among microraptorines. } \\
\text { Lost in "Balaur + Pygostylia" } \\
\text { Lost among Anchiornithinae. } \\
\text { Derived therizinosaurids. }\end{array}$ & $\begin{array}{l}\text { Eumaniraptoran } \\
\text { symplesiomorphy. }\end{array}$ \\
\hline $\begin{array}{l}\text { 13) Elongate manual phalanx p1-III; hi = } \\
0.933 .\end{array}$ & $292(0)$ & $\begin{array}{l}\text { Lost in Tetanurae*. Re-gained in } \\
\text { Microraptoria*, } \\
\text { Halszkaraptorinae*, } \\
\text { Scansorioperygidae and } \\
\text { Pengornithidae*. }\end{array}$ & $\begin{array}{l}\text { Novelty. Convergent with } \\
\text { some paravian lineages. }\end{array}$ \\
\hline $\begin{array}{l}\text { 14) Shelf-like iliac supratrochanteric } \\
\text { process; hi }=0.5 \text {. }\end{array}$ & $1773(1)$ & $\begin{array}{l}\text { "Halszkaraptorinae }+ \\
\text { Unenlagiinae"*, lost in } \\
\text { Unenlagia. }\end{array}$ & Novelty. \\
\hline $\begin{array}{l}\text { 15) Elongate posterolateral crest on femur; } \\
\mathrm{hi}=0.75 \text {. }\end{array}$ & $693(1)$ & $\begin{array}{l}\text { Ceratonykini*. Halszkaraptorinae. } \\
\text { Late-diverging troodontids*. }\end{array}$ & $\begin{array}{l}\text { Novelty. Convergent with a } \\
\text { few maniraptorans. }\end{array}$ \\
\hline $\begin{array}{l}\text { 16) Markedly convex extensor surface of } \\
\text { metatarsal III; hi }=0.5 \text {. }\end{array}$ & $1616(1)$ & Halszkaraptorinae. Balaur. & Novelty. \\
\hline $\begin{array}{l}\text { 17) Unconstricted proximal end of } \\
\text { metatarsal III; hi }=0.941 \text {. }\end{array}$ & $483(0)$ & $\begin{array}{l}\text { Theropod plesiomorphy. } \\
\text { Homoplastically lost among } \\
\text { alvarezsauroids. Homoplastic in } \\
\text { Oviraptorosauria. Lost in } \\
\text { Ornithomimidae, Microraptorinae, } \\
\text { Unenlagiinae and Troodontidae. }\end{array}$ & Theropod plesiomorphy. \\
\hline
\end{tabular}

